City University of New York (CUNY) CUNY Academic Works

\title{
Adherence to the Street Code Predicts an Earlier Anticipated Death
}

Kevin T. Wolff

CUNY John Jay College

Jonathan Intravia

Ball State University

Michael T. Baglivio

Analytic Initiatives

Alex R. Piquero

The University of Texas at Dallas

\section{How does access to this work benefit you? Let us know!}

More information about this work at: https://academicworks.cuny.edu/jj_pubs/463

Discover additional works at: https://academicworks.cuny.edu

This work is made publicly available by the City University of New York (CUNY).

Contact: AcademicWorks@cuny.edu 


\title{
Adherence to the Street Code Predicts an Earlier Anticipated Death
}

\author{
Kevin T. Wolff \\ John Jay College of Criminal Justice \\ New York, NY \\ kwolff@jjay.cuny.edu \\ Jonathan Intravia \\ Ball State Univeristy \\ Department of Criminal Justice and Criminology \\ Muncie, IN \\ jintravia@,bsu.edu \\ Michael T. Baglivio \\ Analytic Initiatives, LLC \\ Odessa, FL \\ mbaglivio@analyticinitiatives.com \\ Alex R. Piquero \\ The University of Texas at Dallas \\ School of Economic, Political and Policy Sciences \\ Dallas, TX \\ apiquero@utdallas.edu
}

Keywords: street code, anticipated age of death, serious juvenile offenders, race/ethnicity

Funding: Support for this project was provided by a PSC-CUNY Award, jointly funded by The Professional Staff Congress and The City University of New York.

Published: Wolff, K. T., Intravia, J., Baglivio, M. T., \& Piquero, A. R. (2020). Adherence to the street code predicts an earlier anticipated death. Journal of Research in Crime and Delinquency, 57(2), 139181. 


\section{Introduction}

For nearly a century, scholarship on street culture has emphasized the concept of fatalism among urban youth (Thrasher, 1927[1963]; Matza, 1964; Miller, 1958). For instance, in his seminal work on gangs, Thrasher (1927) discussed that boys in gangs adhere to deviant values (i.e., committing criminal and delinquent behavior); in turn, the values developed in such subcultures may lead to attitudes toward anticipating an early death. As stated by Thrasher: "the boy usually acquires in the gang an attitude of fatalism, a willingness to take a chance” (p. 392). In a similar vein, Miller's (1958) "focal concern" theory described six values/beliefs that are unique to youth living in lowerclass environments, which include autonomy, toughness, trouble, excitement, smartness, and fate. The concept of fate (or fatalism), according to Miller, corresponds with youth believing that they have little control in their life outcomes because their future is already determined. Thus, early work on subcultures shed light to the notion that shared ideas in subcultures (i.e., crime, violence, conflict) lead to attitudes that are conducive to fatalism, or the belief that life may be cut short.

More recently, Anderson's (1994, 1999) code of the street thesis also explicated how subcultural belief systems may result in urban youth believing (and accepting) that they will experience an early death. In his ethnographic field research of African Americans living in depleted environments, Anderson (1999) discusses a subculture built on the idea of respect that guides interpersonal behavior in the streets, oftentimes through the use of violence. Further, belief systems governed by violence, such as the street code, can influence one's perception of risk. For example, in his discussion on manifesting "nerve," or ways to earn respect in the streets, Anderson (1999:92) argues "a display of nerve can easily provoke a life-threatening response" and that "true nerve expresses a lack of fear of death." Here, Anderson suggests that individuals who embrace a set of attitudes regarding the use of violence affect their beliefs, or perceived risks, regarding death. 
To date, prior studies have identified a number of correlates and consequences of those who anticipate an early death (Agnew, 2002; Brezina et al., 2009; Caldwell, Wiebe, \& Cleveland, 2006; DuRant, Cadenhead, Pendergrast, Slavens, \& Linder, 1994; Hill et al., 1997; Piquero, 2016). Yet, largely neglected from this small, but growing body of research is whether subculture belief systems, such as the street code, influence one's perception of fate, or perceived likelihood of dying early. This gap in research is surprising given that the most recent statistics by the Centers for Disease Control and Prevention (2015) illustrate that the leading cause of death for black males, ages 1534 - consistent to the sample characteristics highlighted in Anderson's street code thesis-is homicide. Thus, examining whether subcultural belief systems that are conducive to violence, such as the street code, influence fatalistic attitudes about dying early can have important implications for understanding the elevated rates of violence present among young people.

In the present study, we contribute and expand upon the subcultural and fatalism literatures in four important ways. First, we examine whether subcultural beliefs about the use of violence affects youths' anticipation of an early death, controlling for several individual- and community-level correlates of both street codes and fatalism—a heretofore unexamined research question within Anderson's thesis. Second, we utilize a sample of deep-end juvenile offenders currently committed to a residential placement within the juvenile justice system in a large, diverse, southeastern state. This population is important because serious juvenile offenders and those in juvenile facilities are at greater risk for experiencing an early violent death (i.e., homicide) (Aalsma et al., 2016; Chassin, Piquero, Losoya, Mansion, Shubert, 2013; Teplin, McClelland, Abram, \& Mileusnic, 2005), are at risk for continuing criminal careers into adulthood (Mulvey et al., 2004), and, in turn, add to the financial toll that their behavior takes on victims and society more generally (Cohen \& Piquero, 2009). In many ways, then, these individuals represent a very important policy-relevant group. Third, because prior research has illustrated that street code attitudes are generalizable to youth beyond African 
American males living in urban environments, such as females, other races/ethnicities, and youth living in suburban and rural areas (Intravia, Wolff, Gibbs, \& Piquero, 2018; Keith \& Griffiths, 2014; Stewart \& Simons, 2006; Taylor, Esbensen, Brick, \& Freng, 2010), we investigate whether the key relationship between street code attitudes and anticipated early death holds across race/ethnicity and gender as outlined in Anderson's thesis. In this regard, our examination of the key relationship across demographic groups allows us to examine the scope of Anderson's argument with respect to fatalism. Finally, we assess whether the results are sensitive to the operationalization of our key dependent variable — anticipated early death—by utilizing two previously used measures of anticipated early death: age of predicted death (continuous), and death by age 35 (dichotomous).

\section{Background}

Elijah Anderson's $(1994,1999)$ Code of the Street thesis focuses on why violence is a conventional theme found predominately among African Americans living in adverse, inner-city environments. According to Anderson (1999:34), residents in these disadvantaged communities experience alienation from society and its institutions (e.g., the police - see Brunson, 2007; Wilson, 1987); and as a result, they feel personally responsible for assuring their own safety (Intravia, Wolff, Stewart, \& Simons, 2014). Thus, the street code is a set of informal rules, primarily surrounding and governing the use of violence, which not only guides social interactions, but also provides self- and family-protection from victimization (Anderson, 1999:33).

The notion of respect is the fundamental foundation of the street code. Often earned in public areas or hangouts through violence, having a strong self-image based on respect is salient because it is believed to reduce victimization. Yet, at the same time, there are always individuals canvassing for respect by manifesting "nerve" through fights, assaults, thefts, and other social ills (Anderson, 1999:92). Thus, even those who hold respect must maintain their reputation, or self-image, through violence, especially when confronted. In other words, it is important not to be "dissed" by others, 
even if it means one's own death (Anderson, 1999:73). As stated by Anderson (1999), “True nerve expresses a lack of fear of death. Many feel it is acceptable to risk dying over issues of respect" (p.92).

The street code is widely observed in the urban, destitute environments discussed by Anderson; however, not everyone living in these communities where the street culture flourishes embraces these sorts of attitudes. In fact, two types of family orientations coexist in these environments_-street families and decent families. Street family structures represent the minority of family units. However, street families often show a lack of patience, lack of consideration for others, and "more fully believe in the code and judge themselves and others according to its values" (Anderson, 1999:45). Decent family units, on the other hand, tend to accept mainstream values, employ strict child-rearing practices, and encourage their children to avoid trouble (1999:38-39). Yet, decent families are fully aware of the street code and understand that they and their children must be able to defend themselves in such a violent milieu. Because decent families understand the streetoriented culture, they underscore the ability to "code-switch" in public settings, which allows individuals from decent families to behave in accordance to both sets of rules (street and decent) in order to survive in the inner city (Anderson, 1999:36). Thus, at an early age, decent children must learn the street culture in order to navigate their environments and protect themselves from harm.

\section{Extant Research on the Street Code}

To date, scholars have examined many of Anderson's $(1994,1999)$ arguments outlined in his thesis, with two topics receiving the most empirical attention as to whether: (1) street code attitudes predict violence and (2) these violent attitudes reduce victimization. One of the first assessments of Anderson's thesis was conducted by Stewart and colleagues (2002). Using a multisite sample of 867 African American family members, the authors found that numerous social psychological variables, including adopting the street code belief system, were significantly related to childhood violence. 
Relatedly, using a sample of 720 African American adolescents from 259 neighborhoods, Stewart and Simons (2006) found that street code attitudes predict violent delinquency and that street code attitudes partially mediate the effects of neighborhood context, family characteristics, and racial discrimination on violence. Prior efforts also illustrate that neighborhood context is an important factor in predicting violence. Specifically, Stewart and Simons (2010) found that not only does neighborhood street culture predict violence independent of individual-level street code attitudes, but neighborhood street culture moderates the effects of street code attitudes on adolescent violence (see also Berg et al., 2012). ${ }^{1}$

While prior research has illustrated support for Anderson's key hypothesis that street codes are prevalent and predict violent occurrences in predominately disadvantaged African American communities, a number of studies have tested these assertions among other samples of the population. For example, Mears and colleagues (2013) examined the street code belief system among a sample of individuals who experienced incarceration and found that street code attitudes predicted inmate violence. Using a diverse sample of school-based youth, Matsuda and colleagues (2013) found that street code attitudes partially mediate the effects of gang membership on violent offending. Other assessments, however, have noted the influence of key concepts moderating the street code and violence relationship. In his assessment of over 400 homeless youth in Toronto, Baron (2017) found that street code attitudes are associated with violence; however, when important factors were considered for moderation (e.g., anger, self-centeredness, low fear of victimization, history of abuse, negative attitudes toward the police), the street code-violence relationship became more pronounced, signifying that "violence can be better understood by the presence, absence, and strength of other key factors" (Baron, 2017:508).

\footnotetext{
${ }_{1}$ Additional research has shown sub/street culture-related philosophies to be linked to violent behavior and aggressive outcomes (see e.g., Bernburg \& Thorlindsson, 2005; Copes, Hochestetler, \& Forsyth, 2013; Markowitz \& Felson, 1998).
} 
Further, street code attitudes have been studied with a broader range of populations and outcomes with varying results. For example, using data from a national sample of adults, with a mean age of 52 years, Piquero et al. (2012) did not find any support that street code attitudes predicted drunk driving, tax deceit, assault, and minor theft. Utilizing a sample of college students, Intravia and colleagues (2017) found that street code attitudes predict involvement in various types of crime (measured in a general crime index; e.g., assault, theft, drunk driving, property damage, drug use) but did not predict involvement in non-criminal activities (e.g., school misbehavior). However, the authors also note that once measures of strain were accounted for, the significant effects of street code on self-reported offending became non-significant. In another study using a multi-site sample of over 900 college-aged adults, Intravia et al. (2018) found street code attitudes predicted violent, property, and drug offending as well as evidence that the street code mediated the effects of low self-control on violent and property crime.

A growing body of research has also examined Anderson's victimization hypothesis. According to Anderson (1994, 1999), individuals adopt the street code belief system, based on violence, to build a strong reputation that safeguards against victimization. Research, however, has shown an opposite pattern. That is, those who embrace the street code are more susceptible to victimization. For example, Stewart, Schreck, and Simons (2006) surveyed 720 African American adolescents from 259 neighborhoods and found that those who adopted street code beliefs were significantly more likely to be violently victimized (see also Schreck, Ousey, Fisher, \& Wilcox, 2012). Further, the positive relationship between street code attitudes and victimization was more pronounced in adolescents living in high-violence neighborhoods (see also Berg et al., 2012). In a more recent assessment, McNeeley and Wilcox (2015a) utilized data from Seattle, Washington, and found that beliefs consistent to the street code were significantly related to various types of victimization experiences, such as being a victim of assault, vandalism, and breaking and entering. In 
a subsequent study, the same authors found the relationship between adopting street code-related attitudes and violent victimization was more likely to occur among those who frequently engage in public activities (compared to those who engage in less public activities away from home; see McNeeley \& Wilcox, 2015b). In another study using the Seattle data, McNeeley and Yuan (2017) found that several code-related beliefs were positively related to emotional fear of crime (i.e., fear of being attacked often) while one specific street code attitude, i.e., that violence is sometimes justified, was positively related to the perceived risk of victimization (i.e., more unsafe neighborhoods). Finally, Kwak and colleagues (2019) examined how codes of violence affected reporting of victimization to the police. Again using the same Seattle data, results showed no relationship in the full sample, but when analyzed across race the authors detected that "Black victims who believed that a code of violence was prevalent in their communities were less likely to report crime to the police" (p.31).

The research reviewed above highlights the prominence of Anderson's street code thesis within the social science literature, as well as its connection to a number of criminal justice-related outcomes, including violence and victimization. Given the compelling theoretical propositions as well as empirical findings regarding the street code's role in individuals' behavior, especially pertaining to the use of violence in everyday life, we believe that it is critical to consider the potential for adherence to the street code to impact one's anticipation of a shortened lifespan. In fact, the ideas presented by Anderson (1999) suggest that violence is not only part of one's social environment but experiencing violence (both directly and indirectly) also plays a role in one's personal belief that they may not live a long life. Prior to describing why we postulate Anderson's street code thesis lends itself well to the prediction of an anticipated early death, we describe the existing empirical research on fatalism, highlighting the salience of fatalistic attitudes among serious adolescent offenders. 


\section{Prior Research on Fatalism}

Social scientists have given some, albeit limited, attention to studying perceptions associated with the anticipation of early death, including some of the risk factors that are related to early death (Agnew, 2002; Brezina et al., 2009; Caldwell, Wiebe, \& Cleveland, 2006; DuRant, Cadenhead, Pendergrast, Slavens, \& Linder, 1994; Hill et al., 1997; Piquero, 2016). This line of research consistently reports a positive association between offending and an anticipated early death, but only two studies have used samples of offenders who are likely to not just be frequently involved in crime but also likely to have a limited life span view. Because we use a sample of deep-end juvenile offenders in residential placement in the current study, it is instructive to provide a more detailed overview of these two studies.

Brezina et al. (2009) explored the link between offending and anticipated early death in a two-pronged analysis. For the first study, they used data from the Add Health, a longitudinal study in the general population while the data for their second analysis came from a series of interviews with active street offenders that probed their cognitive processes and attitudes associated with the risk of an early death. For their quantitative analysis, the authors focused on two outcome variables that respondents provided answers for: the chances they will live to age 35 and the chances they will be killed by age 21 . These two perceptual measures were linked to various types of offending along with a wide array of control variables. As their main interest was on the link between offending and anticipated early death, their focus was on this specific relationship and less on how other variables were related to perceptions of early death. Results from their analysis showed that higher perceptions of an early death were related to more involvement in different types of offending —a result that held with a large number of control variables and a stringent methodological approach. It is also important to point out that their findings linking fatalism to offending did not vary according 
to the two different approaches to measuring age-at-death, whether referencing being killed by 21 or living up to 35 (pp. 1106-1007).

In the qualitative portion of their analysis, their interviews not only replicated the link between anticipated early death and offending, with some offenders specifically noting that they did not think they would make it to age 21, but also shed light on the reality of their lives and the environments they live in. As one offender noted, "Everyday there's a chance I will get robbed, stabbed, or killed" (p. 1115). The authors also asked each of the offenders "What do you think the chances are that you will be killed in the next 5 years?" Without fail, the interviewees did not think about the "distant" future because they just lived day-to-day (p. 1115). As one respondent noted: "I say fuck tomorrow. It's all about today. Might not be a tomorrow. Might get shot. Might get hit by a bus. So get it now. Now, now, now. Next week might as well be next century. Fuck next week. Fuck tomorrow" (p. 1115). In short, their sample of active offenders focused more on the 'right here, right now' and did not care about the future. Importantly as well, their view of fatalism was not constricted to being killed violently per se, but just the overall risk of dying early.

In the second offender-based study, Piquero (2016) used data from the Pathways to Desistance Study, a seven-year study of 1,354 serious adolescent offenders in Philadelphia and Phoenix followed from mid/late-adolescence into early adulthood to investigate not only the determinants of anticipated early death but also to assess whether differences in early death perceptions were related to unique offending trajectories as well as three individual characteristic perceptions. At the baseline interview of the study, respondents were asked "How old do you think you will live to be?” and the analysis considered it both continuously but also, following Brezina et al. (2009), a recoded dead-by-35 measure.

Findings regarding the determinants of anticipated early death showed that males, Hispanics, and respondents who lived in areas characterized by many problems were more likely to report an 
anticipated early age-at-death. Anticipated early death was also able to distinguish between different trajectories of offending. In particular, respondents who were in the lowest offending trajectory group reported the oldest average anticipated age-at-death, while more high rate and late desisting offenders reported an earlier (or younger) average anticipated age-at-death. In the final portion of his analysis, Piquero examined how anticipated age-at-death related to three different perceptual measures: impulse control, perceived rewards, and perceived costs. Findings here showed that a later anticipated age-at-death was related to higher impulse control, higher perceived costs, and lower perceived benefits - all of which are consistent with the reports from Brezina and colleagues that offenders who believe they will die sooner rather than later tend to be more focused on the hereand-now with little appreciation for the long-term.

Although these two studies are important contributions to the research base exploring anticipated early death, most of the research in the fatalism area uses general population samples that are unlikely to have the kind of street experience that Anderson credits as being critical for the emergence and sustainability of the street code. Most importantly, none of the extant research on anticipated early death, regardless of the sample used, has empirically investigated Anderson's hypothesis that subscription to the street code is predictive of an anticipated early death. In the next section, we elaborate upon this potential linkage.

\section{Extending Anderson's Thesis to Fatalism}

In line with earlier subcultural perspectives (Thrasher, 1927; Miller, 1958), Anderson (1994, 1999) contends that the street code belief system influences one's perception/level of risk of dying early. Specifically, those who are fully engrossed in the street code understand that violence is omnipresent in their environment; and part of being heavily invested in a subculture that embraces violence is the understanding that there is a short time appertaining to the streets. Thus, individuals who adhere to the street code have attitudes that not only reflect such violence, but they also 
understand that their risk for dying early is inevitable and largely out of their direct control. On this score, Anderson (1994, p. 94) contends that those persons embodying the street code will likely come to believe that their time on earth will be shortened:

"IN the most fearsome youths such a cavalier attitude toward death grows out of a very limited view of life... They accept this fate; they live on the edge. Their manner conveys the message that nothing intimidates them; whatever turn the encounter takes, they maintain their attack..."

Why would such attitudes conducive to violence affect one's cognitive appraisal, or perceived risk, of dying early? There are several reasons that may shed light on this relationship. First, risk perceptions can be "fast and frugal” (Arkes \& Ayton, 1999; Gigerenzer \& Goldstein, 1996) and may be based on heuristics, intuition, or more general rules of thumb. One explanation for bounded rationality can be explained by the phenomenon known as the sunk cost fallacy, which states that people will continue to make irrational decisions once an investment in something has been made (i.e., time) (Olivola, 2018). Thus, with respect to the street code belief system, those who are invested in the code often earn respect through violence and may continue to place themselves in dangerous situations to continue earning respect, although their decisions may lead to an early death. Risk perceptions can also be dynamic and rapid because individuals may respond to cues or signals in their surroundings, which changes one's risk estimate as it is being perceived (Jacobs \& Cherbonneau, 2018; Piquero, Paternoster, Pogarsky, Loughran, 2011). In addition, one’s perception of risk may be bounded by negative emotions (i.e., anger) and impulsiveness (Jacobs \& Wright, 2010; Topalli \& Wright, 2014), attributes associated with those who embrace attitudes conducive to violence (Intravia et al., 2017, 2018). As Jacobs et al. (2000) noted, many offenders hold antisocial attitudes and commit crime on virtual autopilot believing that whatever is going to happen is going 
to happen (including dying early) and therefore there is little need to worry about one's own mortality.

A second reason as to why street code attitudes may be related to fatalism is due to the type of environment, such as high crime and disadvantage, outlined in Anderson's thesis. For example, Wheaton (1980) argued that fatalism may be a product of socialization effects of low socioeconomic status. Further, although not directly examining fatalism, a number of assessments on concepts similar to fatalism (e.g., powerlessness, helplessness, external locus of control) suggests that (especially disadvantaged) community context(s) can exacerbate feelings that outcomes in life, such as dying early, are outside one's control and simply a fact of life (Ross \& Mirowsky, 2009; Ross, Mirowsky, \& Pribesh, 2001; Wilson, 1987). Further, in environments where violence permeates, individuals may become desensitized and/or adapt to such stressors in a dysfunctional manner (Garbarino, Kostelny, \& Dubrow, 1991), which may increase both the risk of victimization as well the perception that an early death is a distinct possibility. Indeed, using a sample of African American youth living in disadvantaged neighborhoods, Bolland and colleagues (2005) found that witnessing violence, experiencing traumatic stress, and worrying was associated with hopelessness (e.g., "I do not expect to live a very long life"). Similar sentiments have been expressed by Anderson (1999), where he notes "The high death rate among their peers keeps many from expecting to live beyond age twenty-five" (p. 136), and individuals who witness and/or experience violence believe that dying “ain't no big deal” (p. 135). ${ }^{2}$

A third explanation can be found in youths' characteristics and experiences that are related to an anticipated early death. Although not a direct comparison to Anderson's street code thesis,

\footnotetext{
${ }^{2}$ Some research has also raised the possibility of a reciprocal relationship between risk behaviors and measures of anticipated early death (Borowsky et al., 2009; Prince, Epstein, Nurius, Gorman-Smith, \& Henry, 2019). Unfortunately, the current study does not have longitudinal data to examine this possibility of a reciprocal relationship between attitudes conducive to violence and fatalism. We encourage future data collection to shed light into the possibility of reciprocal effects.
} 
many of these indicators are consistent to the themes/concepts discussed in code of the street subculture. For instance, research from health, epidemiology, and social science literatures shows that youth who engage in risky behaviors (e.g., substance abuse, gun access, violence, police arrest) believe that they would not live to the age of 35 (Borowsky, Ireland, \& Resnick, 2009; Duke, Skay, Pettingell, \& Borowsky, 2009). In addition, Duke and colleagues (2009) examined several demographic and family-related correlates on early death perceptions and found that African Americans (as well as other minority groups) and those who live in urban settings are more likely to anticipate death by 35; whereas females, those who live with both parents, those who have stronger parental connections and monitoring, and individuals that feel safe in their neighborhood are less likely to perceive dying by 35. These findings encapsulate much of Anderson's discussion of those who embrace the street code and consequences of investing in the street code. ${ }^{3}$

In short, the discussion above provides evidence of a durable link between contemporaneous attitudes and projections of likely future outcomes. In fact, that linkage lies at the core of human agency itself (see Paternoster, 2017), which is not only iterative (retrospective) and practical (focused on day-to-day) but also profoundly projective (see Emirbayer \& Mische, 1998). Projectivity may be especially powerful among serious offenders; there are few populations more exposed to serious risk on a consistent basis. Acute awareness of danger does more than normalize its existence; it encourages belief systems that allow offenders to navigate the tension between the scary present and an uncertain future. Fatalism provides a mechanism to resolve the dissonance by allowing offenders to take comfort in the fact that as their objective risk rises, so does their lack of

\footnotetext{
${ }^{3}$ In addition, research on suicide ideation illustrates that exposure to adverse environments negatively influence youths' internalizing disorders, such as depressive symptoms (Bernburg, Thorlindsson, \& Sigfusdottir, 2009; Murry, Berkel, Gaylord-Harden, Copeland-Linder, \& Nation, 2011). Research also suggests that youth-parent relationships are important predictors of suicide ideation/attempts, whereas youth who have stronger attachment to their parents are less likely to have suicidal behaviors compared to youth who have negative parental attachment/support (Beautrais, Joyce, \& Mulder, 1996; Haynie, South, \& Bose, 2006; Maimon, Browning \& Brooks-Gunn, 2010).
} 
control. Death is embraced, not feared; it is more an occupational hazard than an existential threat. Fatalism makes this cognitive trick possible by making the future seem not nearly as consequential as the present would dictate.

Although our study offers the first empirical link looking at street code attitudes to fatalism, we are not the only ones (other than Anderson) to proffer such a link. In a small qualitative study of young black male serious offenders detained in an adult jail, Richardson et al. (2013) focused on describing the social context of violence among the youth within the context of Anderson's street code thesis. The data that emerged from the interviews provided important information regarding the acquisition and maintenance of street respect, the viewpoint of violence as a form of labor, the chronic exposure to violence across different contests, social networks, weapon carrying, substance and alcohol use, negotiating violence in jail, and most relevant for our study-mechanisms for coping with chronic exposure to violence. Specifically, the narratives revealed that there was a desensitization to the threat of violent victimization and even dying before young adulthood because they were simply inevitable — what has been referred to in the PTSD literature as 'emotional numbing' (Rich et al., 2005). As one of their subjects, Ice, noted 'No matter what you do out here, you gonna die anyway; you can die stepping off a bus into the street. We all got to die. Beef [disputes] on the street, f-king raw [unprotected sex], it's all the same to me; you can die from anything out here. I mean what's the difference? We all got to die.” So, for Ice, the manner of death was almost inconsequential because of the more general fatalistic attitude he had about his future. As Richardson et al. (2013, p. e9) note: “...adolescents crave respect to such a degree that they will risk their lives to attain and maintain it and feel that it is acceptable to risk dying over the principle of respect." In short, the sense of fatalism is a product of the adoption of attitudes favorable to the street code.

\section{Current Study}


The current study contributes to the body of literature on Anderson's code of the street by assessing the relationship between street code values and anticipated age-at-death among a sample of serious juvenile offenders. In so doing, we not only investigate the extent to which street codes are predictive of an anticipated early death, we also control for a number of risk factors at the individual- and community-level that have been shown in past research to predict fatalism. In accordance with Anderson's $(1994,1999)$ thesis, we first hypothesize that individuals who adhere to the street code are more likely to anticipate dying younger than those who are less entrenched. Further, we investigate whether the key relationship between street code attitudes and anticipated early death holds across race/ethnicity and gender and whether the results are sensitive to the operationalization of an anticipated early death—none of which have been considered in prior research. Consistent with Anderson's (1999) thesis and prior work examining the correlates of anticipated early death (Duke et al., 2009), we hypothesize the relationship between street code attitudes on fatalism would be more pronounced among males and African Americans (as opposed to females and other racial/ethnic subgroups). Prior to presenting the results of our analysis, we provide a description of the data and measures used.

\section{Data}

The current study uses a unique set of both official juvenile justice agency data, as well as original data collected via surveys of youth in juvenile justice residential placement, as part of a larger project, Voices Of Incarcerated youth Concerning Exit Strategies (VOICES). VOICES was developed for the purpose of assessing the fears, challenges, and motivation for changing antisocial behavior regarding transition back to their communities among a large sample of male and female offenders returning from juvenile justice residential placement to a varying array of socioeconomic contexts. The current study leverages the VOICES survey results utilizing respondents' perceptions of their life expectancy post-release as well as measures of Anderson's street code values used in prior empirical research. 
Specifically, after receiving both university and juvenile justice agency IRB approvals during the months of June and July 2018, a large private provider of residential programming in a southeastern state asked juveniles serving a residential placement to participate in the VOICES project. Participation was completely voluntary, and both participants and non-participants were awarded an incentive (e.g., pizza party) after the surveys were completed. The provider operated 1,092 "beds" within the state at the time of the survey, and exactly 1,177 youth were serving a placement between June 18, 2018 and July 31, 2018 (the dates when the hardcopy surveys were mailed to each program and when completed surveys returned). Each survey contained a unique identifier and was provided to the youth represented by that identifier by program staff at each facility. This official identifier allowed the research team to match the survey results back to the juvenile justice agency administrative data housed in its information system (see below).

Completed surveys were stripped of identifying information (except the unique identifier number) and hand-delivered to the co-principal investigator's university office, where they were entered by research staff into a database. Of the 1,177 in-house youth, 874 youth completed at least a portion the survey. Of this sample, 306 respondents were removed from the analysis because they did not provide responses for each of the key measures used in the current study. Following Huang, Curran, Keeney, Poposki, and DeShon (2012), we took a number of steps in order to ensure the reliability of the data collected. First, within the survey there were a number of insufficient effort responding items embedded (Huang, Bowling, Liu, \& Li, 2015). We excluded participants who responded inaccurately to more than one of these items $(n=31)$. Further, both the principal researcher and a graduate assistant reviewed the paper surveys together to determine whether it appeared the surveys had been completed with sufficient effort. Upon examination, an additional 52 surveys were excluded based on hand-checks because the youth indicated the same response for a large number $(10+)$ of questions on the page (i.e., 'Christmas-treed it'), or used a solid line across 
items to indicate a response for multiple questions. ${ }^{4}$ These exclusions resulted in a sample of 485 youth with complete responses for each of the measures used in the current study. Finally, small number of youth were excluded to accommodate the use of tract-level measures capturing the neighborhood conditions from where youth lived prior to placement. Only youth with valid addresses, within the state, were retained, resulting in a final sample of 468 youth. ${ }^{5}$

The final analysis sample was predominately male (78\%), and roughly half Black (49.6\%), with an average age of almost 17 (see Table 1). In comparison to the total 1,177 in-house population, the sample of 468 youth was composed of significantly more females $(21.4 \%$ compared to $11.1 \%$ for the full population, $\mathrm{p}<.001)$ and significantly less Black youth $(49.1 \%$ compared to $63.9 \%, \mathrm{p}<.001)$. However, the sample of respondents included in the analysis did not differ from those who were excluded on ethnicity, proportion that were first arrested at age 12 or under, proportion with 5 or more adjudicated misdemeanors in their criminal history, prior self-reported gang involvement, past drug use (yes/no), or past mental health problems. As such, while more likely to be female and less likely to be Black, the 468 youth analyzed in the current analysis are more or less representative of all youth served in the provider's residential programs (approximately 65\% of the entire state's residential youth) in terms of many prominent risk factors. This is encouraging given the difficulty of obtaining the kind of data needed for the sorts of analyses undertaken in the current study.

The survey responses were then matched to the juvenile justice agency's centralized database which includes information on complete arrest, offense history, justice system placement, and risk/need assessment information for each youth arrested in the state. Central to the current study is

\footnotetext{
${ }^{4}$ All models shown below were re-estimated with this sample of excluded youth included. Results were not sensitive to their exclusion.

${ }^{5}$ A total of 17 youth were excluded because their addresses on file were located in a state other than the current study state.
} 
the risk/needs assessment information captured at admission to the residential program in which the youth was surveyed. This tool is called the Residential Positive Achievement Change Tool (R-

PACT). The R-PACT is administered as a semi-structured interview protocol where the assessor answers multiple forced-choice responses to items across twelve distinct domains. The R-PACT software then produces both static and dynamic risk scores for each domain (except criminal history, which only includes a static risk score). The youth's highest dynamic risk scores are then targeted in case management/ treatment plans for intervention. All R-PACT assessors are bachelor's level case management staff that have successfully completed a 3-day R-PACT assessment and case planning training, as well as a standardized 2-day Motivational Interviewing training. The validity of the R-PACT has been demonstrated in prior work where exit risk scores at release were predictive of subsequent recidivism (Baglivio, Wolff, Jackowski, \& Greenwald, 2017; Hay, Widdowson, Bates, Baglivio, Jackowski, \& Greenwald, 2018). Per department policy, all youth are assessed at admission, reassessed every 90 days, and receive a final assessment just prior to release. As the youth in the current study were at different points of their placement when surveyed, the current study uses the R-PACT at admission to gain an understanding of their risk/needs at the point of entry into the facility, which also predates the administration of the survey.

\section{Measures}

\section{Dependent Measures}

Two dependent measures were examined in the analyses. Consistent with prior work (e.g., Piquero, 2016) the age at which the youth predicted he/she would die was measured as a continuous response, predicted age of death, but was capped at 100 years of age for the 8 percent of youth that wrote in values greater than 100 (mean $=76.5, \mathrm{SD}=24.2$, ranging from 17 to 100$)$. Additionally, as a sensitivity analysis, the continuous item was collapsed into a dichotomous indicator of whether the youth believed he/she would be dead by 35 years of age (mean $=.096, \mathrm{SD}=.295)$. This second 
measure, in addition to being used in previous research on fatalism (Brezina et al., 2009; Duke et al., 2009; Piquero, 2016), is believed to capture those individuals who have relatively limited expectations for their life. For example, 35 years represents less than half the life expectancy of the average American living today (Xu, Murphy, Kochanek, \& Bastian, 2016). Additionally, as the sample under study is comprised of adolescent offenders, for most the expectation of dying before 35 suggests they believe they may have already lived a large proportion, essentially half, of their life. Accordingly, this binary measure is believed capture youth who think about their future in a fundamentally different way than those who anticipate dying later, sometimes much later, in life. Independent Measures

Code of the Street. Of primary interest to the current study, is a measure of the extent to which youth held beliefs that were consistent with adopting the street code. Consistent with prior work (Intravia et al., 2016; Stewart et al., 2006), a street code index was created from seven Likert scale items assessing agreement with: 1) When someone disrespects you, it is important that you use physical force or aggression to teach him or her not to disrespect you; 2) If someone uses violence against you, it is important that you use violence against him or her to get even; 3) People will take advantage of you if you do not let them know how tough you are; 4) People do not respect a person who is afraid to fight physically for his/her rights; 5) Sometimes you need to threaten people to get them to treat you fairly; 6) It is important to show others that you cannot be intimidated; and 7) People tend to respect a person who is tough and aggressive. Each item had response options of strongly agree, agree, neither agree or disagree, disagree, and strongly disagree. Each item was reverse coded such that higher values indicate a stronger agreement with the code of the street. An average of the seven items was calculated in order to obtain a total score representing the extent to which the youth held beliefs that were consistent with adopting the street code (mean=2.83; $\mathrm{SD}=.855$; alpha $=.845)$. The distribution of this measure is shown in Figure 1. 


\section{Figure 1 About Here}

Demographics. Demographic items included sex $($ male $=1)$ and a series of dichotomous indicators of race and ethnicity. Specifically, Black $(=1)$ and Hispanic $(=1)$ were included, where ethnicity supersedes race such that all Black youth are non-Hispanic and Hispanic youth may be either Black or White. Additionally, the youth's age at admission to the program was included as a continuous measure $($ mean $=16.8, \mathrm{SD}=1.25)$. Finally, because youth receive a number of services during residential placement that may be related to future orientation and values surrounding the use of violence (e.g., cognitive behavioral therapy), we control for the time spent in the program prior to the administration of the VOICES survey. This was captured using number of days (logged) the youth was in the program at the time of completing the VOICES survey (mean=4.91, $\mathrm{SD}=.898$ ).

Criminal History Indicators. Additional controls for prominent risk factors (derived from RPACT items) included age at first arrest, prior felony adjudications, prior against-person/violent felony adjudications, prior sexual offending felony adjudications, and gang involvement. Age at first arrest was captured according to the classifications used in the R-PACT of 12 years old or under at first arrest, 13 to 14, 15, 16, and over 16 (coded 0-4, with higher values indicating an older age at first arrest). Prior felony adjudications distinguished between none, one, two, or three or more (coded 1-4, with higher values indicating a greater extent of prior adjudications for felony offending). To assess prior violence, prior against-person felony offending distinguished those with none, one or two, and three or more prior against-person felony adjudications (coded 1-3, with higher values indicative of more extensive prior violence). Youth with prior felony adjudications for sexual offending felonies were classified as those with none, one, or two or more prior sexual felony adjudications (coded 1-3, with higher values indicating a greater history of being adjudicated for sexual felony offending). Whether the youth self-reported a history of gang membership/association was captured dichotomously (no/yes). Notably, in the event the youth had been verified as a gang 
member or associate by law enforcement as per state statute, that indication would be used to override the youth's self-report (this information is maintained as an "alert" in the juvenile justice agencies information system).

Self-control. The youth's self-control was drawn from several items within the RPACT. The youth's ability to exhibit self-control was captured using a categorical measure including lacks techniques to use self-control, rarely uses such techniques, sometimes uses techniques, and often uses techniques for exhibiting self-control (coded 1-4, with higher values indicative of more selfcontrol). The second item assessed whether the youth believed he/she can avoid/stop antisocial behavior, somewhat believes antisocial behavior is controllable, or believes his/her antisocial behavior is out of his/her control (coded 1-3). Third, the youth's level of impulsivity was assessed as using self-control/usually thinking before acting, sometimes thinking before acting, impulsive, or highly impulsive/usually acts before thinking (coded 1-4, with higher values indicative of higher impulsivity). Finally, the youth's ability to control impulsive behavior was assessed as lacks techniques to control impulsive behavior, rarely uses techniques to control impulsive behavior, sometimes uses such techniques, or no problems with impulsivity/often uses techniques to control impulsive behavior (coded 0-3, with higher values indicating less impulsivity). All items were recoded (as necessary) such that higher values were indicative of greater self-control. Each of these items were first standardized, and an index of self-control was created by summing the standardized scores $($ alpha $=.764)$.

Mental Health and Substance Use Problem Indicators. In addition to the youth-level characteristics described above, we include a number of indicators of a youth's mental health and substance abuse. Due to the lack of specificity in our dependent variables regarding how youth perceive they will die, these measures of mental health and substance abuse, which may be indicative of the potential for self-harm, represent potentially important confounding variables in the relationship between street 
code values and our measures of fatalism. Specifically, the current analysis uses a number of items drawn from the R-PACT which assess mental health and substance use/abuse concerns including a diagnosed mood disorder, extent of depressive symptoms, suicidal ideation, and past drug problems prior to admission. Mood disorder diagnosis was a dichotomous indicator ( $1=$ yes), which had to be formally diagnosed by a qualified mental health practitioner. Feelings of depression classified youth with no such history, history of occasional feelings, and youth with consistent feelings/impairment in daily life due to feelings of depression (coded 1-3, with higher values indicative of a greater extent of depressive symptoms/impairment). Our measure of suicidal ideation identified those with recent serious thoughts of or plans to commit suicide as well as those who had recently attempted suicide from those with no such thoughts or actions (with $13.2 \%$ of youth having recently considered or attempted suicide). Additionally, an indicator of whether the youth's past drug use caused problems with school, family, health, peer associations, or in contributing to criminal behavior was included, classifying youth with no past drug use, those with past use, and those whose use caused problems in such life domains (coded 0-2, with higher values indicative of greater substance use/abuse).

Neighborhood Level Contextual Measures. As the extent to which the youth exhibits values indicative of the code of the street may be in part based on where he/she resided prior to placement, the current study controls for three contextual indicators (measured at the census tract level): resource deprivation, immigrant concentration, and residential instability. Similar contextual measures have been used in prior work examining a number of criminological outcomes, including their impact on homicide (Kubrin \& Weitzer, 2003), fear of crime (Roman \& Chalfin, 2008) as well as juvenile offenders more generally (e.g., Rodriguez, 2013; Wolff, Baglivio, Piquero, Vaughn, \& DeLisi, 2015). Data used to construct the neighborhood level measures were drawn from the 20132017 American Community Survey (ACS) 5-year estimates for census tracts in the current study 
state (U.S. Census Bureau, 2014). The 468 youth resided in 393 census tracts across the state prior to placement, with an average of 1.4 youth per tract (ranging from 1 to 4 ).

A resource deprivation index (Land, McCall, \& Cohen, 1990) was created from six census tract-level variables including the proportion of individuals living below the poverty line, median family income (logged and reverse coded), the proportion of female-headed households, the unemployment rate, the percentage of the population who are non-Hispanic Black, and the percentage of residents with a high school degree or equivalent. Consistent with previous research, these variables are strongly correlated to one another at the census tract level, and factor analyses indicated that these variables loaded on a single factor in our sample. The items were standardized and combined to form an additive index of resource deprivation (alpha $=.878$ ).

Immigrant concentration was measured as an index that included percentage foreign born and percentage latino/a. Both indicators were standardized and combined to create an immigrant concentration index ( $\alpha=.824$, with higher values indicating more immigrant concentration). This measure is consistent with prior research, which has examined the effect of immigrant concentration on crime and delinquency (Desmond \& Kubrin, 2009; Lee et al., 2001; Reid, Weiss, Adelman, \& Jaret, 2005; Sampson, Morenoff, \& Raudenbush, 2005; Wolff et al., 2015; Wolff et al., 2017).

Finally, an index of residential instability was created from an item of percent renters and percent in the same home from the year prior (reverse coded). Both indicators were standardized and combine to create the index of residential instability $(\alpha=.707)$. Residential (in)stability has figured prominently in prior work regarding neighborhood conditions and offending (e.g., Boggess \& Hipp, 2010; Sampson, Raudenbush, \& Earls, 1997), including juvenile offender recidivism (Wolff, Baglivio, Intravia, Greenwald, \& Epps, 2017).

\section{Analysis}


The current analysis uses bivariate and multivariate approaches to examine the relationship between street code values and two measures of perceived age-at-death. Prior to our multivariate assessment, Spearman's rank correlations were utilized to explore the relationships present between the key variables used in the analysis for the current sample of justice-involved youth. In addition to assessing for the possibility of collinearity issues, these bivariate relationships provide preliminary evidence related to the proposed relationship between street code values and fatalism. Importantly, Spearman's rho is a nonparametric measure of correlation, which represents a more appropriate statistical measure of association than the traditional Pearson's correlation coefficient given the categorical nature of many of our measures.

After establishing the bivariate relationship between the measures used in the current study we utilize both ordinary least squares (OLS) and logistic regression models to assess the relationship between street code values and our measures of anticipated early death while controlling for a number of youth-level characteristics. This combined approach helps to guard that our results are not sensitive to the operationalization of the dependent variable, especially since OLS regression may be sensitive to the non-normal distribution of responses within the continuous measure of anticipated age-at-death. Finally, after assessing the association between adherence to the street code and anticipated age-at-death for the full analysis sample, we disaggregate by key youth-level characteristics (race and sex) in order to determine whether this relationship is conditional on the youth characteristics. ${ }^{6}$ This is done by estimating the same model on a total of six different subsamples (i.e., male, female, black, non-black, black males, and non-black males) and comparing the obtained coefficients to determine whether any observed effects vary by race or sex of the

\footnotetext{
${ }^{6}$ Our examination across demographic groups is not without merit. Recall that Kwak et al. (2019) found that race moderated the relationship between street code attitudes and reporting victimization to the police (see also Duke et al., 2009)
} 
respondent. ${ }^{7}$ Finally, because in a small number of cases more than one youth resided in the same neighborhood prior to residential placement, robust standard errors that account for the clustering of youth within neighborhoods were estimated. ${ }^{8}$

\section{Table 1 about Here}

\section{Results}

Table 1 contains the descriptive statistics for each of the measures included in the current analysis for the final sample of 468 youth. This sample was largely male (78.2\%), and Black (49.6\%), with an average age of 16.8 years old. Nearly 23 percent of the sample had been diagnosed with a mood disorder, and 10.7 percent reported prior gang involvement. The average anticipated age-atdeath reported was just over 76.5 years of age $(\mathrm{SD}=24.24)$ and 9.6 percent of the youth reported that they would not live past the age of 35. In comparison to Piquero (2016), the average age of anticipated death reported by the respondents in the current study was slightly higher (76.5 vs. 70.9 years), and approaches the American average life expectancy (78.6 years; Xu, Murphy, Kochanek, \& Bastian, 2016). However, a larger proportion of respondents reported an anticipated age at death of less than 35 years old when compared to both Brezina and colleagues (2009), who among a general sample of the population observed 3.6 percent of the population anticipated dying before age 35 , and Piquero (2016) who reported 6 percent indicated they would live to less than 35.

\section{Table 2 about Here}

Table 2 displays the bivariate correlations between the key variables included in the current study. Each of our dependent measures of perceived age-at-death were significantly related to street code values in the anticipated direction. Specifically, higher values on our street code index were

\footnotetext{
${ }^{7}$ Sample composition and small cell counts prevented a separate analysis of Black female youth.

${ }^{8}$ The degree of clustering present among youth in the analysis sample did not permit a full multilevel modeling approach as the number of youth within each neighborhood was insufficient to model the within-neighborhood variation through the use of a random intercept. The use of clustered standard errors assures that the results are not impacted by the nonindependence of observations stemming from multiple youth within a number of neighborhoods.
} 
negatively related to the continuous measure of perceived age-at-death $(r=-.276, \mathrm{p}<.05)$, while they were positively and significantly related to death by $35(\mathrm{r}=.239, \mathrm{p}<.05)$. Each dependent variable was also significantly related to age at first offense, the number of prior felonies a youth had, prior history of sexual offending, and gang membership. Two additional measures, index of self-control and depression were negatively associated with anticipated age-at-death, yet not significantly related to dead by 35 .

\section{Table 3 about Here}

Table 3 presents the results of our multivariate analyses. The first two models display the OLS regression results, where the continuous measure of perceived age-at-death was regressed on youth level covariates (Model 1) and then with the inclusion of street code values (Model 2). The same models are repeated with the dichotomous outcome in a logistic regression equation and are shown in Models 3 and 4. The results displayed in Model 1 suggest that of the youth- and neighborhood-level characteristics considered, only prior felony offending and prior sexual offending were significantly related to anticipated age-at-death. Specifically, youth with a greater number of prior felonies anticipated an earlier death $(\mathrm{b}=-2.91, \mathrm{p}<.05)$ as did youth with a history of sex offenses $(\mathrm{b}=-7.46, \mathrm{p}<.05)$. Model 2 includes our measure of street code values as an additional independent variable, which was significantly and negatively related to anticipated age-atdeath $(b=-9.30, p<.05)$, indicating that attitudes in line with the street code were related to perceptions of an early death. In Model 3, which includes the results of a logistic regression model where death before 35 represents the outcome $(=1)$, we observed a significant effect of race, where Blacks were over three times more likely to anticipate dying before the age of $35(\mathrm{OR}=3.44, \mathrm{p}<$ .05). Again, youth with more prior felony offenders were more likely to believe they would die before the age of $35(\mathrm{OR}=1.64, \mathrm{p}<.05)$ as did youth with sexual offending histories $(\mathrm{OR}=2.55, \mathrm{p}$ $<.05)$. Gang members were also likely to anticipate themselves dying at a younger age $(\mathrm{OR}=2.27, \mathrm{p}$ 
$<.05)$. Finally, the results shown in Model 4 suggest that youth who identify more strongly with the street code are more likely to anticipate dying before age 35 , net of the included control variables $(\mathrm{OR}=3.08, \mathrm{p}<.05)$

The results of Model 2 and Model 4 are displayed in Figure 1 where predicted values for each outcome measure are shown at varying levels of the street code values index, holding all other covariates at their means. The results on the left-hand side of Figure 1 display the clear negative relationship between adherence to the street code and anticipated age-of-death. To further contextualize this effect, consider that the average youth in this sample who reported responses consistent with a low adherence to the street code (-2SD) had a predicted perceived age-of-death of 92.6 years old, compared to 60.8 years for a youth who reported a strong adherence to the code of the street (+2SD) — a difference of over 30 less years of anticipated time alive. Displayed on the right-hand side of Figure 1 are the predicted probabilities of early death given different levels of street code beliefs. Again, we observe a clear relationship between street code beliefs and expecting to die before age 35 with stronger street code values being associated with a greater probability of expecting to die before age 35 .

Figure 2 \& Table 4 about Here

Table 4 displays the results for a series of regression models run on samples disaggregated by the race and sex of the youth. These analyses were designed to assess whether the relationship between street code values and anticipated early death are conditional on select youth characteristics. As Anderson's street code thesis was developed in large part from observations in disadvantaged Black communities in inner city Philadelphia, focusing predominately on males and Blacks (and the intersection being Black males), the current study sought to examine whether the effects of a street code ethos holds across race/ethnic and gender subgroups. We ran the full OLS and logistic 
regression models shown in Table 3 on six subsamples, for a total of 12 models estimated. ${ }^{9}$

Importantly, while Table 4 displays only the focal estimates, all control variables are also included (results available upon request). Looking across models, greater adherence to the street code was associated with a younger age of anticipated death. This was true among each of the six subsamples analyzed (i.e., males, females, Blacks, non-Blacks, Black Males, and non-Black males). ${ }^{10}$

Following Paternoster, Brame, Mazerolle, and Piquero (1998), a number of z-tests for equality of the OLS regression coefficients (i.e., slope difference test) were conducted to determine whether the observed differences (in the effect of street code values on perceived age-of-death) were statistically significant between the groups specified (examining only those which were mutually exclusive). Results of these ancillary tests, also displayed in Table 4, suggest that the effect of street code values on perceived age-of-death did not vary significantly between the different subgroups analyzed.

In the second set of split-sample models estimated, which examined the effect of street codes on dead by 35 using logistic regression, results were a little less consistent across the groups analyzed. The key difference found was that for female youth street codes were not significantly related to the likelihood of dying before 35. Greater adherence to the street code was, however, positively associated with the perception of an early death among each of the other five samples analyzed (although the magnitude if the relationship varied slightly between Black and non-Black youth).

\section{Figure 3 about Here}

Figure 3 shows the predicted probabilities of early death at different levels of street code values for each of the groups estimated. A relatively clear picture of the relationship between street

\footnotetext{
${ }^{9}$ We decided to use this approach so that readers can see the precise coefficient estimates across groups, which would not be possible with an interactive approach.

${ }^{10}$ Again, due to small sample sizes we were unable to estimate a black female only model.
} 
code values and anticipated early death was observed. ${ }^{11}$ For each of the subgroups, except female youth, the predicted probability increases significantly as youth report a greater adherence to street code values, controlling for all youth- and neighborhood-level characteristics included. These results are discussed in more detail below along with theoretical implications and suggestions for future research.

\section{Discussion}

Anderson's street code thesis has proved to be an important contribution to several disciplines in the social sciences. Bringing together urban sociology, anthropology, and criminology into one overall perspective, Anderson shed important light on the plight of (largely) African American youth living in distressed and disadvantaged inner-city communities. Faced with those circumstances and the need to demand respect on the street, Anderson argued, youth develop a set of attitudes that guide their daily interactions. Because of their surroundings and the few opportunities these youth perceive to be available to escape such communities, a great many of them come to the realization that they need to live for the here and now, with little attention heeded to adulthood in large part because so many of their colleagues do not live long enough to see it.

Not surprisingly, Anderson's ideas captivated the minds and scholarly attention of many social scientists, mainly in criminology, who focused on the key relationship between street code attitudes and violence/victimization. Yet, despite this important line of work, several other of Anderson's expectations have yet to be empirically examined. Accordingly, we set out to extend this line of research in important ways by empirically assessing the relationship between street code values and anticipated age-at-death among a sample of serious juvenile offenders currently

\footnotetext{
${ }^{11}$ It was suggested by an anonymous reviewer that perhaps, adherence to the street code may affect a belief of invulnerability (i.e., late age of death). We also explored the potential for a non-linear relationship between street code values and anticipated early death to exist. The results of a simple bivariate test provided no indication of a non-linear relationship among the youth in the current sample. Youth who indicated greater support for the street code were more likely to anticipate an earlier age at death.
} 
committed to a residential placement within the juvenile justice system in a large, diverse, southeastern state.

Our findings were compelling. Despite controlling for an important array of factors at both the individual and community levels that are related to perceived age-at-death, street code attitudes were significantly predictive of an earlier anticipated age-at-death-with predicted probabilities showing a discrepancy of almost 30 years of life lost between the extreme values on our street code index. These findings add to the small body of qualitative literature, which has suggested a link exists between street code attitudes and fatalism (Rich and Grey, 2005; Richardson et al. 2013). Moreover, as past research has not considered these issues across demographic groups, we extended our analysis by considering whether the relationship between street code attitudes and fatalism were endemic to only one sex or race/ethnicity. That was not the case. Almost without fail, street code attitudes predicted an earlier age-at-death for all of the subgroups we considered, thereby evidencing the generality of Anderson's street code thesis with respect to fatalism at least with this sample of serious juvenile offenders. ${ }^{12}$ This secondary finding adds to the body of research that street codes may be a salient predictor of individual behavior regardless of race and/or sex (Intravia, Wolff, Gibbs, \& Piquero, 2018; Keith \& Griffiths, 2014; Stewart \& Simons, 2006; Taylor, Esbensen, Brick, \& Freng, 2010).

Importantly, while the results of our analysis suggest street code values are significantly related to one's anticipated age-of-death among this sample of serious adolescent offenders, we must note that the magnitude of this effect may be less dramatic than may have been anticipated given Anderson's compelling description of the street code in action. For example, after accounting for the other predictors in the model, youth who reported the greatest adherence to the street code

\footnotetext{
12 Out of all the tests of this relationship conducted, only the effect of street code attitudes on death by 35 among the small sample of female juvenile offenders failed to achieve statistical significance. This was not the case, however, in the model predicting anticipated age at death where a significant relationship was observed for each subgroup analyzed.
} 
$(+2 \mathrm{SD})$ had a predicted an earlier anticipated age of death that was about 18 or so years younger than the average life expectancy (shown in Figure 2). Furthermore, only $9.6 \%$ of the sample reported an earlier anticipated age-of-death that was less than 35 years old. While greater adherence to the street code was associated with a higher probability of anticipating dying before 35 among all but one of the subgroups analyzed, as a whole, the majority of the sample saw themselves living well into adulthood. With these facts in mind, we must acknowledge that while our results suggest that adherence to the street code is in fact associated with an anticipated earlier death, this does not necessarily mean that the youth in our sample believe they will, in fact, die early from adhering to the street code.

We believe that our findings contribute to the larger body of work on the street code thesis as well as fatalism more generally; yet, our enthusiasm must be tempered somewhat by some of the limitations of our data. First, we have a very select sample of individuals, so generalizing our findings to other offenders (and non-offenders) in other states remains an important question. Although we do not see this as a fatal issue, in large part because justice-involved youth are precisely the policyrelevant group from an intervention perspective (Mulvey et al., 2004), replication of our results remains necessary. Second, the dependent variable used in the current study lacks some degree of specificity. That is, we are unable to say for sure that respondents who anticipate an early death are anticipating one that is violent in nature. It is possible that our measure of early death confounds both violent death with that due to other causes (illness, suicide, etc.). Future research would be wise to include a measure that captures not only the timing of one's anticipated death, but the nature of it. We note, however, that our two measures of early death are in-line with those of prior research (Brenzina et al., 2009 and Piquero, 2016) which included findings that offending trajectories differed by anticipated early death. 
Third, the sample of youth analyzed was not fully representative of the in-house population of youth at the time the survey was conducted. Specifically, youth in the analysis sample were significantly more likely to be males and less likely to be Black. Importantly, however, those youth included in the analysis did not differ from those who were excluded on most of the covariates considered including age at first offense and offending history. Nevertheless, these differences have important implications for the generalizability of our results. It is possible that the relationships observed may differ among a broader sample of youth. Importantly, we have attempted to control for these differences by including a number of characteristics which may be correlated with both adherence to the street code and our measures of fatalism. We hope future research will be in a position to collect even stronger data to assess the relationship at hand, but nevertheless believe that our preliminary investigation into this research question adds to the knowledge base in several areas within criminology. Fourth, due to limited sample sizes, we were unable to examine whether the main relationships considered in this study held for other racial/ethnic groups. Studying this issue more broadly would help to continue to amass evidence in support for (or not) the generalizability of the street code thesis.

Finally, it is possible that our measurement of street code values using self-report methods among an incarcerated sample of youth suffers from a kind of self-serving bias. Youth committed by the juvenile court to a correctional facility (for criminal activity) may be hesitant to report violent attitudes during their time in residential placement. Unfortunately, the current study leveraged the opportunity to collect data from this sample while the youth were in state custody and we are currently unable to assess the magnitude of this effect. Future research measuring street code values and fatalistic attitudes among a community sample would to confirm the findings presented here.

Perhaps the more important issue our findings underscore is the melancholy with which these youth view their lives_especially at such a young age. Young offenders with a pessimistic 
outlook on later life may use that orientation to justify their continued participation in criminal activity (Piquero, 2016) and be resistant to prosocial opportunities. Understanding why they believe what they do, while disheartening, is critical for society more generally as we seek to ensure children have all of the adequate socialization, experiences, and opportunities for life success. Prior work has highlighted the role of safe and stable environments in fostering resilience and hope among those most at risk, but more work to identify effective interventions is needed (Ross \& Hill, 2002). The cost in not doing so are high, not just financially (Cohen \& Piquero, 2009), but more importantly for the youth and their families. There is no more pressing social issue than ensuring that young children see that they have hope for a future, one filled with success and not a shortened existence.

Toward this end, there are some policy proscriptions that emanate from our research that may hold relevance for prevention and especially intervention efforts. Notably, school-based prevention programs may be a useful venue to combat the development of a street code ethos within young people. Programs such as G.R.E.A.T. have been shown to reduce future violence and gang membership, potential bi-products of higher street code attitudes. In the event families are willing participants, multi-systems family-based interventions, such as Multisystemic Therapy (MST; Henggeler \& Borduin, 1990) and Functional Family Therapy (FFT; Alexander \& Sexton, 2002) could address family concerns, provide support, and leverage prosocial community resources. With respect to the development of a street code belief system, potential programs aimed at enhancing self-control are viable prevention strategies as well; such programs have demonstrated efficacy at this point (Piquero, Jennings, Farrington, Diamond, \& Reingle Gonzalez, 2016). As the current study focused on deep-end juvenile offenders in residential placement, many of which already highly endorse a street code, as evidenced above, intervention efforts within juvenile justice settings should employ cognitive behavioral therapeutic approaches and curricula based on cognitive restructuring and skill building. Interestingly, such CBT interventions have the strongest demonstrated recidivism 
reduction effects among all therapeutic treatment types for juvenile offenders (Lipsey, 2009). We would be remiss, however, to not mention that youth residing in deleterious socioeconomic contexts most often suffer from severe lack of prosocial opportunities that even the best evidence-based programs may be hard-pressed to combat. Local, state, and federal government agencies should attend to those matters so to ensure that all children in all circumstances receive the resources and opportunities needed for life success. 


\section{References}

Aalsma, M.C., Lau, K.S., Perkins, A.J., Schwartz, K., Tu, W., Wiehe, S.E., Monahan, P. \& Rosenman, M.B. 2016. "Mortality of Youth Offenders Along a Continuum of Justice System Involvement." American Journal of Preventive Medicine 50(3):303-310.

Agnew, R. 2002. "Experienced, Vicarious, and Anticipated Strain: An Exploratory Study on Physical Victimization and Delinquency." Justice Quarterly 19:603-32.

Alexander, J. F., \& Sexton, T. L. 2002. "Functional Family Therapy: A Model for Treating HighRisk, Acting-Out Youth.” In F. W. Kaslow \& J. Lebow Eds., Comprehensive Handbook of Psychotherapy: Integrative/Eclectic pp. 111-132. New York, NY: John Wiley.

Anderson, E. 1994. “The Code of the Streets.” The Atlantic May, pp. 81-94.

Anderson, E. 1999. Code of the Street. New York: Norton.

Arkes, H. R., \& Ayton, P. (1999). The sunk cost and Concorde effects: Are humans less rational than lower animals?. Psychological Bulletin 125(5), 591-600.

Baglivio, M. T., Wolff, K. T., Jackowski, K., \& Greenwald, M. A. 2017. “A Multilevel Examination of Risk/Need Change Scores, Community Context, and Successful Reentry of Committed Juvenile Offenders." Youth Violence and Juvenile Justice 15:38-61.

Baron, S. W. 2017. "It's More than The Code: Exploring the Factors that Moderate the Street Code's Relationship with Violence.” Justice Quarterly 34:491-516.

Beautrais, A. L., Joyce, P. R., \& Mulder, R. T. 1996. "Risk Factors for Serious Suicide Attempts among Youths Aged 13 through 24 Years." Journal of the American Academy of Child \& Adolescent Psychiatry 35(9): 1174-1182.

Berg, M. T., Stewart, E. A., Schreck, C. J., \& Simons, R. L. 2012. "The Victim-Offender Overlap in Context: Examining the Role of Neighborhood Street Culture. Criminology 50:359-90.

Bernburg, J. G., \& Thorlindsson, T. 2005. "Violent Values, Conduct Norms, and Youth Aggression: A Multilevel Study in Iceland." The Sociological Quarterly 46:457-78.

Bernburg, J. G., Thorlindsson, T., \& Sigfusdottir, I. D. 2009. "The Spreading of Suicidal Behavior: The Contextual Effect of Community Household Poverty on Adolescent Suicidal Behavior and the Mediating Role of Suicide Suggestion.” Social Science \& Medicine 68(2): 380-389.

Boggess, L. N., \& Hipp, J. R. (2010). "Violent crime, residential instability and mobility: Does the relationship differ in minority neighborhoods?" Journal of Quantitative Criminology, 26(3), 351370.

Bolland, J. M., Lian, B. E., \& Formichella, C. M. 2005. "The Origins of Hopelessness among InnerCity African-American Adolescents.” American Journal of Community Psychology 36: 293-305. 
Borowsky, I. W., Ireland, M., \& Resnick, M. D. 2009. "Health Status and Behavioral Outcomes for Youth who Anticipate a High Likelihood of Early Death.” Pediatrics 124(1):e81-e88.

Brezina, T., Tekin, E., \& Topalli, V. 2009. “'Might not be a Tomorrow”': A Multimethods Approach to Anticipated Early Death and Youth Crime.” Criminology 47, 1091-1129.

Brunson, R. K. 2007. “Police Don't Like Black People’: African-American Young Men's Accumulated Police Experiences.” Criminology \& Public Policy 61:71-101.

Caldwell, R. M., Wiebe, R. P., \& Cleveland, H. H. 2006. “The Influence of Future Certainty and Contextual Factors on Delinquent Behavior and School Adjustment among African American Adolescents." Journal of Youth and Adolescence 35:591-602.

Chassin, Laurie, Alex R. Piquero, Sandra H. Losoya, Andre D. Mansion, \& Carol A. Schubert. 2013. "Joint Consideration of Distal and Proximal Predictors of Premature Mortality among Serious Juvenile Offenders." Journal of Adolescent Health 52: 689-696.

Cohen, M.A., \& Piquero, A.R. 2009. "New Evidence on the Monetary Value of Saving a High Risk Youth.” Journal of Quantitative Criminology 25:25-49.

Copes, H., Hochstetler, A., \& Forsyth, C. J. 2013. "Peaceful Warriors: Codes for Violence among Adult Male Bar Fighters." Criminology 51:761-94.

Desmond, S., \& Kubrin, C. (2009). "The power of place: Immigrant communities and adolescent violence." The Sociological Quarterly, 50, 581-607.

Duke, N. N., Skay, C. L., Pettingell, S. L., \& Borowsky, I. W. 2009. “Adolescent Perception of Premature Risk for Death: Contributions from Individual and Environmental Contextual Factors." Academic Pediatrics 9(4): 256-262.

DuRant, R. H., Cadenhead, C., Pendergrast, R. A., Slavens, G., \& Linder, C. W. 1994. "Factors Associated with the Use of Violence among Urban Black Adolescents." American Journal of Public Health 84:612-17.

Emirbayer, M., \& Mische, A. (1998). "What is agency?." American Journal of Sociology, 103(4), 9621023.

Garbarino, J., Kostelny, K., \& Dubrow, N. 1991. "What Children Can Tell us About Living in Danger." American Psychologist 46(4): 376-383.

Gigerenzer, G. and Goldstein, D.G. 1996. "Reasoning the Fast and Frugal Way: Models of Bounded Rationality.” Psychological review 103(4):650-669.

Hay, C., Widdowson, A. O., Bates, M., Baglivio, M. T., Jackowski, K., \& Greenwald, M. A. 2018. "Predicting Recidivism among Released Juvenile Offenders in Florida." Youth Violence and Juvenile Justice 16:97-116. 
Haynie, D. L., South, S. J., \& Bose, S. 2006. "Residential Mobility and Attempted Suicide among Adolescents: An Individual-Level Analysis.” The Sociological Quarterly 47(4): 693-721.

Henggeler, S. W., \& Borduin, C. M. 1990. Family Therapy and Beyond: A Multisystemic Approach to Treating the Behavior Problems of Children and Adolescents. Pacific Grove, CA: Brooks/Cole.

Hill, E., Ross, L. T., \& Low, B. S. 1997. "The Role of Future Unpredictability in Human RiskTaking." Human Nature 8:287-325.

Huang, J. L., Curran, P. G., Keeney, J., Poposki, E. M., \& DeShon, R. P. (2012). “Detecting and deterring insufficient effort responding to surveys." Journal of Business and Psychology, 27(1), 99114.

Huang, J. L., Bowling, N. A., Liu, M., \& Li, Y. (2015). "Detecting insufficient effort responding with an infrequency scale: Evaluating validity and participant reactions." Journal of Business and Psychology, 30(2), 299-311.

Intravia, J., Wolff, K. T., Stewart, E. A., \& Simons, R. L. 2014. "Neighborhood-level Differences in Police Discrimination and Subcultural Violence: A Multilevel Examination of Adopting the Code of the Street." Journal of Crime and Justice 37:42-60.

Intravia, J., Wolff, K. T., Gibbs, B. R., \& Piquero, A. R. 2017. "Violent Attitudes and Antisocial Behavior: Examining the Code of the Street's Generalizability among a College Sample." Deviant Behavior 38:957-74.

Intravia, J., Gibbs, B. R., Wolff, K. T., Paez, R., Bernheimer, A., \& Piquero, A. R. 2018. "The Mediating Role of Street Code Attitudes on the Self-Control and Crime Relationship." Deviant Behavior 39:1305-21.

Jacobs, B.A. \& Cherbonneau, M. 2018. "Perceived Sanction Threats and Projective Risk Sensitivity: Auto theft, Carjacking, and the Channeling Effect." Justice Quarterly 35(2): 191-222.

Jacobs, B. A., \& Wright, R. 2010. "Bounded Rationality, Retaliation, and the Spread of Urban Violence." Journal of Interpersonal Violence 25(10): 1739-1766.

Keith, S., \& Griffiths, E. 2014. "Urban Code or Urban Legend: Endorsement of the Street Code among Delinquent Youth in Urban, Suburban, and Rural Georgia." Race and Justice 4: 270298.

Kubrin, C. E., \& Weitzer, R. (2003). "Retaliatory homicide: Concentrated disadvantage and neighborhood culture." Social Problems, 50(2), 157-180.

Kwak, H., Dierenfeldt, R., \& McNeeley, S. (2019). "The code of the street and cooperation with the police: Do codes of violence, procedural injustice, and police ineffectiveness discourage reporting violent victimization to the police?.” Journal of Criminal Justice, 60, 25-34. 
Land, K. C., McCall, P. L., \& Cohen, L. E. (1990). "Structural covariates of homicide rates: Are there any invariances across time and social space?" American Journal of Sociology, 4, 922-963.

Lee, M., Martinez, R., \& Rosenfeld, R. (2001). “Does immigration increase homicide?” The Sociological Quarterly, 42, 559-580.

Leventhal, T., \& Brooks-Gunn, J. 2000. “The Neighborhoods They Live In: The Effects of Neighborhood Residence on Child and Adolescent Outcomes." Psychological Bulletin 126:30937.

Lipsey, M. W. 2009. "The Primary Factors that Characterize Effective Interventions with Juvenile Offenders: A Meta-analytic Overview." Victims and Offenders 4:124-47.

Maimon, D., Browning, C. R., \& Brooks-Gunn, J. 2010. "Collective Efficacy, Family Attachment, and Urban Adolescent Suicide Attempts. Journal of Health and Social Behavior 51(3): 307-324.

Markowitz, F. E., \& Felson, R. B. 1998. “Social-demographic Attitudes and Violence.” Criminology 36:117-138.

Matsuda, K. N., Melde, C., Taylor, T. J., Freng, A., \& Esbensen, F. A. 2013. "Gang Membership and Adherence to the "Code of the Street"." Justice Quarterly 30:440-68.

Matza, D. 1964. Delinquency and Drift. New York, NY: Wiley.

Mears, D. P., Stewart, E. A., Siennick, S. E., \& Simons, R. L. 2013. "The Code of the Street and Inmate Violence: Investigating the Salience of Imported Belief Systems. Criminology 51:695728.

McNeeley, S., \& Wilcox, P. 2015a. "The Code of the Street and Violent Versus Property Crime Victimization." Violence and Victims, 30:1049-67.

McNeeley, S., \& Wilcox, P. 2015b. "Street Codes, Routine Activities, Neighbourhood Context and Victimization." British Journal of Criminology 55:921-43.

McNeeley, S., \& Yuan, Y. (2017). “A Multilevel Examination of the Code of the Street's Relationship with Fear of Crime.” Crime \& Delinquency 63(9), 1146-1167.

Miller, W.B. 1958. "Lower Class Culture as a Generating Milieu of Gang Delinquency.” Journal of Social Issues 14:5-19.

Mulvey, E.P., Steinberg, L., Fagan, J., Cauffman, E., Piquero, A. R., Chassin, L., et al. 2004. 'Theory and Research on Desistance from Antisocial Activity among Serious Adolescent Offenders." Youth Violence and Juvenile Justice 2:213-36.

Murry, V., Berkel, C., Gaylord-Harden, N. K., Copeland-Linder, N., \& Nation, M. 2011. "Neighborhood Poverty and Adolescent Development." Journal of Research on Adolescence 21(1): 114-128. 
Olivola, C.Y. 2018. “The Interpersonal Sunk-Cost Effect.” Psychological Science 29(7):1072-1083.

Paternoster, R. 2017. Happenings, acts, and actions: articulating the meaning and implications of human agency for criminology. Journal of Developmental and Life Course Criminology, 3, 350-372.

Paternoster, R., Brame, R., Mazerolle, P., \& Piquero, A. 1998. "Using the Correct Statistical Test for the Equality of Regression Coefficients." Criminology 36:859-66.

Piquero, A. R. 2016. “'Take My License n'All That Jive, I Can’t See... 35’: Little Hope for the Future Encourages Offending Over time.” Justice Quarterly 33:73-99.

Piquero, A.R., Moffitt, T.E., \& Lawton, B. 2005. “The Contribution of Individual, Familial, and Neighborhood-level Risk Factors to Life-Course-Persistent Offending.” In D.F. Hawkins and K. Kempf-Leonard Eds., Our Children, Their Children: Confronting Racial and Ethnic Differences in American Juvenile Justice pp. 202-244. Chicago: University of Chicago Press.

Piquero, A. R., Intravia, J., Stewart, E., Piquero, N. L., Gertz, M., \& Bratton, J. 2012. "Investigating the Determinants of the Street Code and its Relation to Offending Among Adults." American Journal of Criminal Justice 37:19-32.

Piquero, A. R., Jennings, W. G., Farrington, D. P., Diamond, B., \& Reingle Gonzalez, J. M. 2016. “A Meta-analysis Update on the Effectiveness of Early Self-Control Improvement Programs to Improve Self-Control and Reduce Delinquency." Journal of Experimental Criminology 12:249-64.

Piquero, A.R., Paternoster, R., Pogarsky, G. \& Loughran, T. 2011. "Elaborating the Individual Difference Component in Deterrence Theory." Annual Review of Law and Social Science 7: 335360.

Prince, D. M., Epstein, M., Nurius, P. S., Gorman-Smith, D., \& Henry, D. B. 2019. "Reciprocal Effects of Positive Future Expectations, Threats to Safety, and Risk Behavior Across Adolescence." Journal of Clinical Child \& Adolescent Psychology 48(1): 54-67.

Reid, L., Weiss, H., Adelman, R., \& Jaret, C. (2005). "The immigration-crime relationship: Evidence across US metropolitan areas." Social Science Research, 34, 757-780.

Rich, J.A., \& Grey, C.M. 2005. "Pathways to recurrent trauma among young Black men: traumatic stress, substance use, and the 'code of the street"'. American Journal of Public Health, 95, 816824.

Richardson, J.B., Brown, J., \& Van Brakle, M. 2013. "Pathways to early violent death: the voices of serious violent youth offenders." American Journal of Public Health, 103, e5-e16.

Rodriguez, N. (2013). "Concentrated disadvantage and the incarceration of youth: Examining how context affects juvenile justice." Journal of Research in Crime and Delinquency, 50(2), 189-215.

Roman, C.G., \& Chalfin, A. 2008. "Fear of walking outdoors: a multilevel ecologic analysis of crime and disorder." American Journal of Preventive Medicine, 34(4), 306-312. 
Ross, C. E., \& Mirowsky, J. 2009. "Neighborhood Disorder, Subjective Alienation, and Distress." Journal of Health and Social Behavior 50(1): 49-64.

Ross, C. E., Mirowsky, J., \& Pribesh, S. 2001. "Powerlessness and the Amplification of Threat: Neighborhood Disadvantage, Disorder, and Mistrust.” American Sociological Review 66(4), 568591.

Ross, L. T., \& Hill, E. M. (2002). "Childhood unpredictability, schemas for unpredictability, and risk taking." Social Behavior and Personality: an International Journal, 30(5), 453-473.

Sampson, R. J., Morenoff, J., \& Raudenbush, S. W. (2005). "Social anatomy of racial and ethnic disparities in violence." American Journal of Public Health, 95, 224-232.

Sampson, R., J., Raudenbush, S. W., \& Earls, F. (1997). "Neighborhoods and violent crime: A multilevel study of collective efficacy." Science, 277, 918-924.

Schreck, C. J., Ousey, G. C., Fisher, B. S., \& Wilcox, P. 2012. "Examining What Makes Violent Crime Victims Unique: Extending Statistical Methods for Studying Specialization to the Analysis of Crime Victims." Journal of Quantitative Criminology 28:651-71.

Stewart, E. A., \& Simons, R. L. 2006. "Structure and Culture in African American Adolescent Violence: A Partial Test of the 'Code of the Street' Thesis.” Justice Quarterly 23:1-33.

Stewart, E. A., \& Simons, R. L. 2010. "Race, Code of the Street, and Violent Delinquency: A Multilevel Investigation of Neighborhood Street Culture and Individual Norms of Violence." Criminology 48:569-605.

Stewart, E. A., Schreck, C. J., \& Simons, R. L. 2006. “'I Ain't Gonna Let No One Disrespect Me’ Does the Code of the Street Reduce or Increase Violent Victimization among African American Adolescents?" Journal of Research in Crime and Delinquency 43:427-58.

Stewart, E. A., Simons, R. L., \& Conger, R. D. 2002. "Assessing Neighborhood and Social Psychological Influences on Childhood Violence in an African-American Sample." Criminology 40:801-30.

Taylor, T.J., Esbensen, F.A., Brick, B.T. \& Freng, A., 2010. "Exploring the Measurement Quality of an Attitudinal Scale of Street Code-Related Violence: Similarities and Differences across Groups and Contexts." Youth Violence and Juvenile Justice 8(3):187-212.

Teplin, Linda A., Gary M. McClelland, Karen M. Abram, \& Darinka Mileusnic. 2005. "Early Violent Death among Delinquent Youth: A Prospective Longitudinal Study." Pediatrics 115: 15861593.

Thrasher, F. M. 1927/1963. The Gang: A Study of One Thousand Three Hundred Thirteen Groups in Chicago. 
Topalli, V., \& Wright, R. 2014. "Affect and the Dynamic Foreground of Predatory Street Crime." Affect and Cognition in Criminal Decision Making 42-57.

U.S. Census Bureau. (2014). American community survey 2008-2012 5-year summary file technical documentation. Washington, DC: U.S. Department of Commerce. Retrieved from http://www2.census.gov/ acs20135yr/summaryfile/ACS2013SFTechDoc.pdf.

Wheaton, B. 1980. “The Sociogenesis of Psychological Disorder: An Attributional Theory.” Journal of Health and Social Behavior 21:100-124.

Wilson, W.J. 1987. The Truly Disadvantaged: The Inner City, The Underclass, and Public Policy. Chicago: University of Chicago.

Wolff, K. T., Baglivio, M. T., Intravia, J., Greenwald, M. A., \& Epps, N. (2017). "The mobility of youth in the justice system: Implications for recidivism." Journal of Youth and Adolescence, 46, 1371-1393.

Wolff, K. T., Baglivio, M. T., Piquero, A. R., Vaughn, M. G., \& DeLisi, M. (2015). “The triple crown of antisocial behavior: Effortful control, negative emotionality, and community disadvantage." Youth Violence and Juvenile Justice, 14(4), 350-366.

Wolff, K., Baglivio, M., Intravia, J., \& Piquero, A. (2015). “The protective impact of immigrant concentration on juvenile recidivism: A statewide analysis of youth offenders." Journal of Criminal Justice, 43, 522-531.

Wolff, K. T., Intravia, J., Baglivio, M. T., \& Piquero, A. R. (2017). “The protective impact of immigrant concentration on juvenile recidivism: A multilevel examination of potential mechanisms." Crime \& Delinquency, advance online publication, doi: 10.1177/0011128717739608.

Xu, J., Murphy, S., Kochanek, K.D., Bastian, B.A., “Deaths: Final Data for 2013”. National Vital Statistics Reports, 64(2). 
Table 1: Descriptive statistics for the analysis of street code values and anticipated age-at-death $(n=468)$

\begin{tabular}{|c|c|c|c|c|}
\hline & Mean & SD & Min & Max \\
\hline 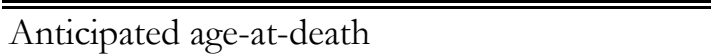 & 76.526 & 24.245 & 17 & 100 \\
\hline Dead by 35 & 0.096 & 0.295 & 0 & 1 \\
\hline Street code values & 2.83 & 0.858 & 1 & 5 \\
\hline Male & 0.782 & 0.413 & 0 & 1 \\
\hline Black & 0.496 & 0.501 & 0 & 1 \\
\hline Hispanic & 0.152 & 0.359 & 0 & 1 \\
\hline Age & 16.765 & 1.25 & 12.36 & 20.16 \\
\hline Age of first offense & 1.147 & 1.05 & 0 & 4 \\
\hline Prior felonies & 3.244 & 0.9 & 1 & 4 \\
\hline Prior against-person felonies & 1.635 & 0.642 & 1 & 3 \\
\hline Prior sex felonies & 1.109 & 0.369 & 1 & 3 \\
\hline Gang member & 0.107 & 0.309 & 0 & 1 \\
\hline Self-control scale & -0.001 & 0.708 & -1.77 & 1.77 \\
\hline Mood disorder diagnosis & 0.229 & 0.42 & 0 & 1 \\
\hline Depression & 1.782 & .780 & 1.00 & 3.00 \\
\hline Suicidal Ideation & .132 & .339 & .00 & 1.00 \\
\hline History of substance use problem & 1.237 & .681 & .00 & 2.00 \\
\hline Time in program (months) & 4.908 & .898 & 1.39 & 7.16 \\
\hline Resource deprivation (neighborhood-level) & .044 & .782 & -1.97 & 2.30 \\
\hline Immigrant concentration (neighborhood-level) & .006 & .917 & -1.03 & 4.39 \\
\hline Residential instability (neighborhood-level) & .041 & .850 & -1.64 & 2.90 \\
\hline
\end{tabular}




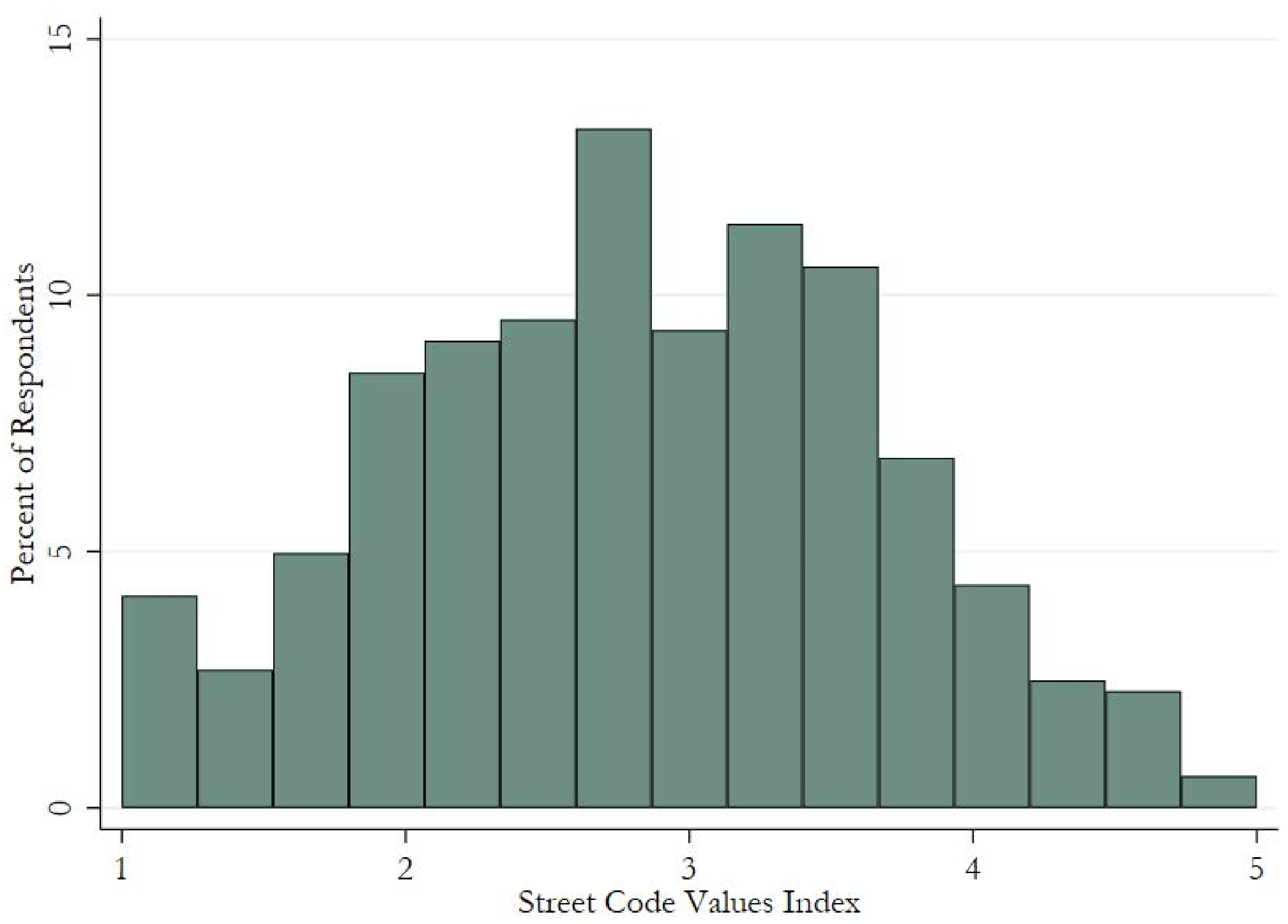


Table 2: Spearman's Rho correlations between key measures in analysis of street codes and anticipated age-at-death ( $\mathrm{n}=468$ )

\begin{tabular}{|c|c|c|c|c|c|c|c|c|c|c|c|c|c|c|c|c|c|c|c|c|c|c|}
\hline & & (1) & $(2)$ & (3) & $(4)$ & (5) & $(6)$ & $(7)$ & (8) & 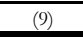 & $(10)$ & $(11)$ & $(12)$ & (13) & $(14)$ & $2(15)$ & $(16)$ & $(17)$ & $(18)$ & $(19)$ & $(20)$ & $(21)$ \\
\hline (1) & Anticipated age-at-death & 1.0000 & & & & & & & & & & & & & & & & & & & & \\
\hline (2) & Dead by 35 & $-0.5143^{*}$ & 1.0000 & & & & & & & & & & & & & & & & & & & \\
\hline (3) & Street code values & $-0.2764^{*}$ & $0.2386^{*}$ & 1.0000 & & & & & & & & & & & & & & & & & & \\
\hline (4) & Male & -0.0371 & -0.0385 & $0.1165^{*}$ & 1.0000 & & & & & & & & & & & & & & & & & \\
\hline (5) & Black & -0.0197 & $0.1115^{*}$ & $0.1980^{*}$ & 0.0265 & 1.0000 & & & & & & & & & & & & & & & & \\
\hline (6) & Hispanic & $0.0961^{*}$ & -0.0167 & -0.0173 & 0.0501 & $-0.4193^{*}$ & 1.0000 & & & & & & & & & & & & & & & \\
\hline (7) & Age & 0.0259 & -0.0726 & -0.0525 & $0.1877 *$ & 0.0063 & -0.0048 & 1.0000 & & & & & & & & & & & & & & \\
\hline (8) & Age of first offense & $0.1440^{*}$ & $-0.1292^{*}$ & -0.0415 & $0.1323^{*}$ & $-0.1135^{*}$ & 0.0720 & $0.4277^{*}$ & 1.0000 & & & & & & & & & & & & & \\
\hline (9) & Prior felonies & $-0.0917 *$ & $0.1239 *$ & $0.1161^{*}$ & $0.1659^{*}$ & $0.1912^{*}$ & -0.0624 & -0.0312 & $-0.2579 *$ & 1.0000 & & & & & & & & & & & & \\
\hline (10) & Prior against-person felonies & 0.0108 & 0.0540 & -0.0494 & -0.0754 & $0.1817^{*}$ & 0.0031 & -0.0713 & $-0.2217 *$ & $0.1826^{*}$ & 1.0000 & & & & & & & & & & & \\
\hline (11) & Prior sex felonies & $-0.1026^{*}$ & $0.0988^{*}$ & -0.0787 & $0.1479 *$ & -0.0420 & -0.0491 & $0.1307^{*}$ & 0.0107 & -0.0896 & $0.2270^{*}$ & 1.0000 & & & & & & & & & & \\
\hline (12) & Gang member & $-0.1061^{*}$ & $0.1218^{*}$ & $0.1298^{*}$ & 0.0150 & 0.0168 & 0.0273 & -0.0397 & $-0.1140^{*}$ & 0.0494 & 0.0686 & 0.0360 & 1.0000 & & & & & & & & & \\
\hline (13) & Self-control scale & $-0.0968^{*}$ & 0.0439 & 0.0161 & $-0.1526^{*}$ & -0.0293 & -0.0022 & $-0.1446^{*}$ & -0.0185 & -0.0629 & -0.0452 & 0.0022 & 0.0420 & 1.0000 & & & & & & & & \\
\hline (14) & Mood disorder diagnosis & -0.0334 & 0.0295 & -0.0319 & $-0.2795^{*}$ & $-0.2141 *$ & 0.0392 & -0.0584 & -0.0129 & -0.0523 & $0.1045^{*}$ & -0.0249 & 0.0423 & 0.0496 & 1.0000 & & & & & & & \\
\hline (15) & Depression & $-0.0969 *$ & 0.0156 & -0.0097 & $-0.2659 *$ & $-0.3006^{*}$ & -0.0107 & -0.0207 & -0.0522 & $-0.1576^{*}$ & -0.0505 & 0.0090 & 0.0144 & $0.1091 *$ & $0.3017^{*}$ & 1.0000 & & & & & & \\
\hline (16) & Suicidal Ideation & -0.0458 & 0.0222 & 0.0693 & $-0.1448^{*}$ & $-0.1731 *$ & -0.0423 & $-0.1056^{*}$ & -0.0852 & -0.0553 & 0.0251 & 0.0307 & -0.0127 & $0.0984^{*}$ & $0.2375^{*}$ & $0.2797 *$ & 1.0000 & & & & & \\
\hline (17) & History of substance use problem & -0.0257 & 0.0349 & -0.0172 & -0.0557 & $-0.1496^{*}$ & 0.0782 & 0.0691 & 0.0068 & 0.0277 & $-0.1103^{*}$ & $-0.2057 *$ & $0.1551 *$ & $0.1562^{*}$ & 0.0487 & $0.1483^{*}$ & 0.0112 & 1.0000 & & & & \\
\hline (18) & Time in program (months) & 0.0661 & 0.0035 & $-0.1132^{*}$ & 0.0888 & 0.0484 & 0.0076 & 0.0009 & -0.0489 & 0.0819 & $0.2107^{*}$ & $0.1863^{*}$ & -0.0148 & -0.0334 & -0.0556 & -0.0611 & -0.0148 & $-0.1288 *$ & 1.0000 & & & \\
\hline (19) & Resource deprivation & 0.0189 & 0.0682 & $0.1231^{*}$ & -0.0286 & $0.4037^{*}$ & -0.0397 & -0.0116 & -0.0858 & $0.1389 *$ & $0.2032^{*}$ & -0.0028 & 0.0858 & -0.0383 & $-0.1380^{*}$ & $-0.1259 *$ & -0.0606 & -0.0894 & $0.0921^{*}$ & 1.0000 & & \\
\hline (20) & Immiggant concentration & 0.0343 & -0.0509 & -0.0449 & 0.0593 & -0.0367 & $0.3450^{*}$ & $0.1588^{*}$ & 0.0351 & $0.1238^{*}$ & 0.0799 & -0.0559 & -0.0046 & -0.0083 & -0.0193 & -0.0402 & $-0.1185^{*}$ & $0.1190^{*}$ & -0.0027 & 0.0063 & 1.0000 & \\
\hline (21) & Residential instability & 0.0755 & 0.0223 & $0.1201 *$ & -0.0236 & $0.2814^{*}$ & 0.0287 & -0.0185 & -0.0253 & $0.0942^{*}$ & $0.0978^{*}$ & -0.0532 & 0.0227 & 0.0300 & -0.0542 & $-0.1335^{*}$ & 0.0000 & -0.0382 & -0.0147 & $0.4169 *$ & $0.1715^{*}$ & 1.0000 \\
\hline
\end{tabular}

0.05 


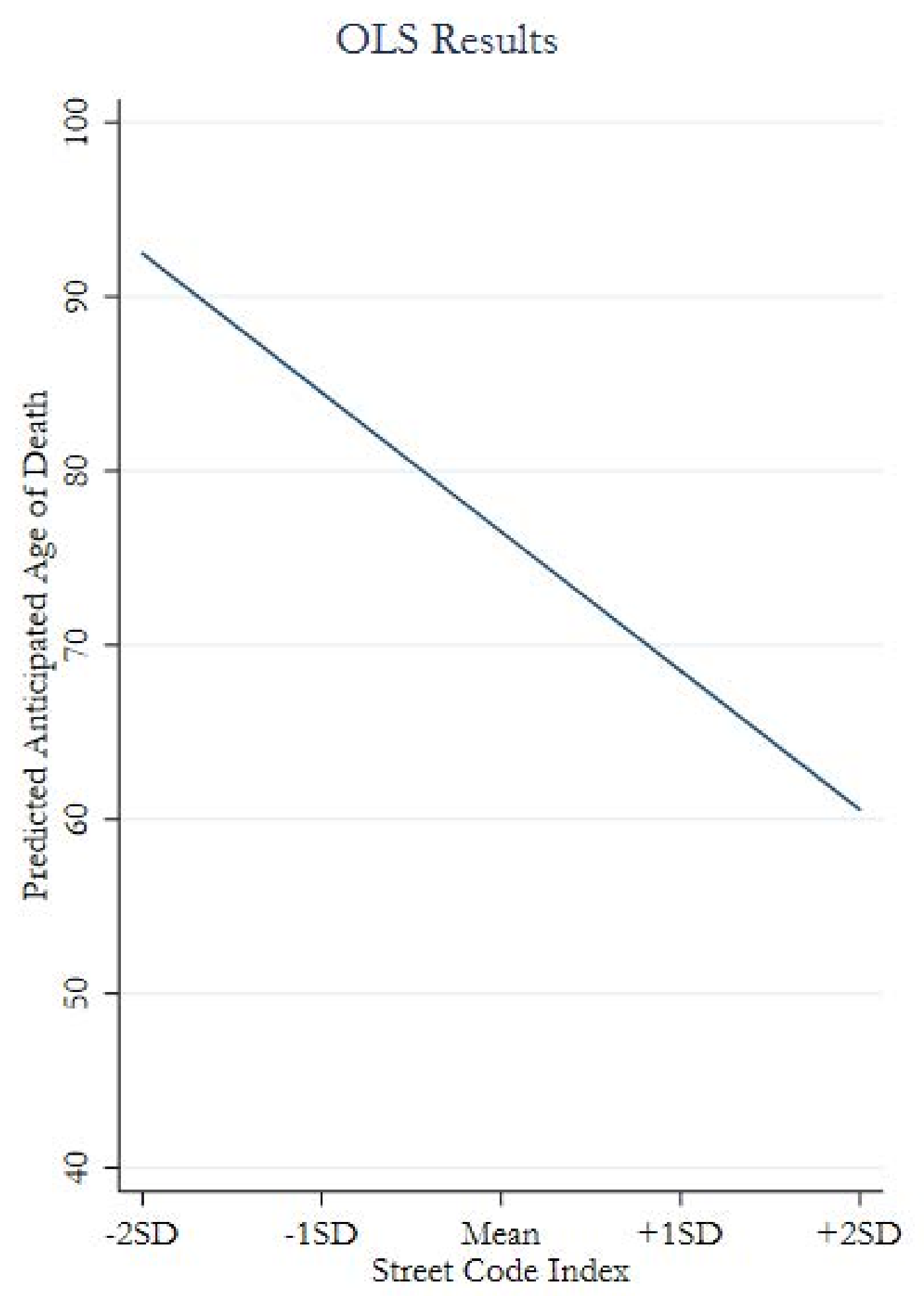

Logistic Results

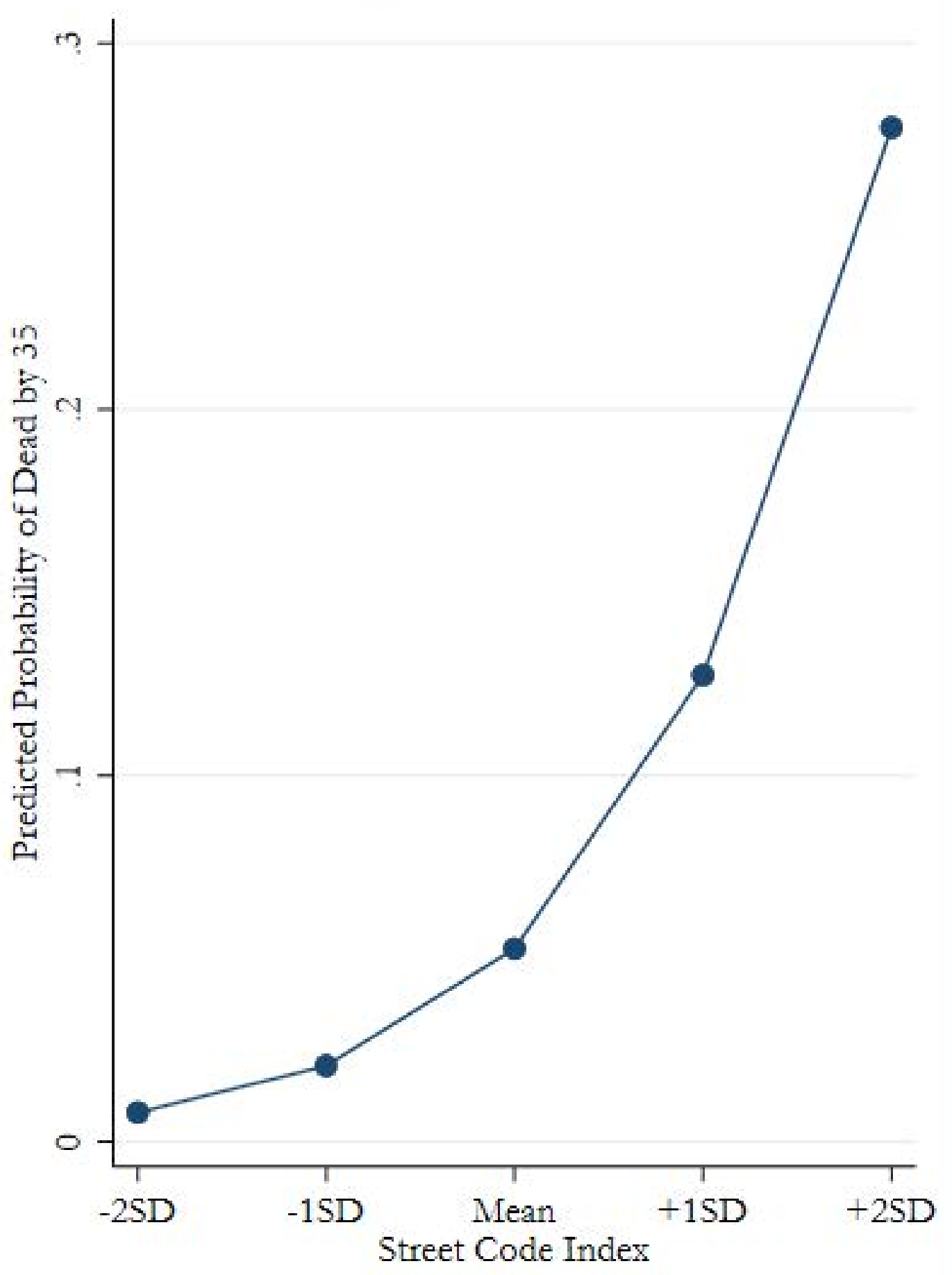


Table 3: Multivariate results for the analysis of street code values and fatalism $(\mathrm{n}=468)$

\begin{tabular}{|c|c|c|c|c|}
\hline & \multicolumn{2}{|c|}{ OLS Regression Predicting Anticipated Age-at-death } & \multicolumn{2}{|c|}{ Logistic Regression Predicitng Dead by 25} \\
\hline & $\begin{array}{c}\text { Model 1: Controls } \\
\text { b / CI95 }\end{array}$ & $\begin{array}{c}\text { Model 2: W/Street Codes } \\
\text { b / CI95 }\end{array}$ & $\begin{array}{c}\text { Model 3: Controls } \\
\text { OR / CI95 } \\
\end{array}$ & $\begin{array}{c}\text { Model 4: W/Street Codes } \\
\text { OR / CI95 }\end{array}$ \\
\hline \multirow[t]{2}{*}{ Street code values } & "-- & $-9.299 * *$ & - & $3.076^{* *}$ \\
\hline & -- & {$[-11.835,-6.763]$} & -- & {$[1.839,5.146]$} \\
\hline \multirow[t]{2}{*}{ Male } & -2.190 & .733 & .702 & .504 \\
\hline & {$[-8.492,4.113]$} & {$[-5.405,6.871]$} & {$[.291,1.695]$} & {$[.192,1.323]$} \\
\hline \multirow[t]{2}{*}{ Black } & -4.027 & -.341 & $3.436 * *$ & 2.721 \\
\hline & {$[-9.802,1.748]$} & {$[-5.901,5.219]$} & {$[1.352,8.733]$} & {$[.985,7.516]$} \\
\hline \multirow[t]{2}{*}{ Hispanic } & 1.515 & 3.878 & 2.407 & 2.129 \\
\hline & {$[-5.711,8.740]$} & {$[-3.178,10.935]$} & {$[.777,7.463]$} & {$[.664,6.824]$} \\
\hline \multirow[t]{2}{*}{ Age } & .498 & .307 & .895 & .885 \\
\hline & {$[-1.611,2.606]$} & {$[-1.763,2.378]$} & {$[.665,1.204]$} & {$[.647,1.210]$} \\
\hline \multirow[t]{2}{*}{ Age of first offense } & 2.122 & 2.211 & .821 & .803 \\
\hline & {$[-.317,4.561]$} & {$[-.073,4.494]$} & {$[.520,1.295]$} & {$[.506,1.275]$} \\
\hline \multirow[t]{2}{*}{ Prior felonies } & $-2.913^{*}$ & -2.128 & $1.641 *$ & 1.566 \\
\hline & {$[-5.569,-.257]$} & {$[-4.627, .372]$} & {$[1.032,2.610]$} & {$[.960,2.557]$} \\
\hline \multirow[t]{2}{*}{ Prior against-person felonies } & 2.306 & 1.346 & .827 & .823 \\
\hline & {$[-1.876,6.488]$} & {$[-2.578,5.269]$} & {$[.500,1.367]$} & {$[.490,1.382]$} \\
\hline \multirow[t]{2}{*}{ Prior sex felonies } & $-7.461^{*}$ & $-8.666^{* *}$ & $2.550^{*}$ & $3.629 * *$ \\
\hline & {$[-13.673,-1.248]$} & {$[-14.695,-2.637]$} & {$[1.224,5.310]$} & {$[1.589,8.287]$} \\
\hline \multirow[t]{2}{*}{ Gang member } & -7.861 & -4.449 & $2.265^{*}$ & 1.511 \\
\hline & {$[-16.409, .688]$} & {$[-12.551,3.653]$} & {$[1.004,5.109]$} & {$[.609,3.752]$} \\
\hline \multirow[t]{2}{*}{ Self-control ccale } & -1.324 & -1.037 & 1.019 & 1.006 \\
\hline & {$[-4.277,1.629]$} & {$[-3.871,1.797]$} & {$[.649,1.600]$} & {$[.627,1.613]$} \\
\hline \multirow[t]{2}{*}{ Mood disorder diagnosis } & -1.245 & -1.175 & 1.296 & 1.440 \\
\hline & {$[-7.025,4.536]$} & {$[-6.919,4.568]$} & {$[.571,2.940]$} & {$[.591,3.506]$} \\
\hline \multirow[t]{2}{*}{ Depression } & -2.978 & -1.890 & 1.191 & 1.053 \\
\hline & {$[-6.252, .297]$} & {$[-4.943,1.164]$} & {$[.729,1.948]$} & {$[.649,1.708]$} \\
\hline \multirow[t]{2}{*}{ Suicidal Ideation } & -2.839 & -.173 & 1.479 & 1.205 \\
\hline & {$[-10.251,4.572]$} & {$[-6.942,6.595]$} & {$[.535,4.086]$} & {$[.443,3.278]$} \\
\hline \multirow[t]{2}{*}{ History of substance use problem } & -.795 & -1.398 & 1.308 & 1.382 \\
\hline & {$[-4.287,2.697]$} & {$[-4.696,1.900]$} & {$[.772,2.218]$} & {$[.810,2.359]$} \\
\hline \multirow[t]{2}{*}{ Time in program (months) } & 1.384 & .310 & 1.002 & 1.189 \\
\hline & {$[-1.100,3.867]$} & {$[-2.018,2.639]$} & {$[.736,1.363]$} & {$[.835,1.693]$} \\
\hline \multirow[t]{2}{*}{ Resource Deprivation } & -.741 & -.466 & 1.017 & .956 \\
\hline & {$[-4.038,2.557]$} & {$[-3.672,2.740]$} & {$[.632,1.637]$} & {$[.553,1.652]$} \\
\hline \multirow[t]{2}{*}{ Immigrant Concentration } & -.615 & -1.310 & .896 & .974 \\
\hline & {$[-3.550,2.320]$} & {$[-4.042,1.422]$} & {$[.563,1.427]$} & {$[.601,1.578]$} \\
\hline \multirow[t]{2}{*}{ Residential Instability } & 1.373 & 1.790 & 1.028 & 1.014 \\
\hline & {$[-1.611,4.357]$} & {$[-1.049,4.628]$} & {$[.660,1.601]$} & {$[.653,1.576]$} \\
\hline \multirow[t]{2}{*}{ Constant } & $84.157^{* *}$ & $112.766^{* *}$ & .016 & $.000^{* *}$ \\
\hline & {$[50.883,117.431]$} & {$[78.758,146.774]$} & {$[.000,1.968]$} & {$[.000, .070]$} \\
\hline
\end{tabular}

$* \mathrm{p}<.05, * * \mathrm{p}<.01 ; \mathrm{b}=$ unstandardized regression coefficient. OR= Odds ratio. CI95 $=95 \%$ confidence interval. Models account for the clustering of youth within neighborhoods. 
Table 4: Split sample regression results for analysis of street code values and fatalism

\begin{tabular}{|c|c|c|c|c|c|c|}
\hline & Male Youth & Female Youth & Black Youth & $\begin{array}{l}\text { Non-Black Youth } \\
\qquad(\mathrm{n}=236)\end{array}$ & $\begin{array}{l}\text { Black Male Youth } \\
\qquad(\mathrm{n}=184)\end{array}$ & $\begin{array}{l}\text { Non-Black Male Youth } \\
\qquad(\mathrm{n}=182)\end{array}$ \\
\hline & $\mathrm{b}(\mathrm{OR}) / \mathrm{CI} 95$ & $\mathrm{~b}(\mathrm{OR}) / \mathrm{CI} 95$ & $\mathrm{~b}(\mathrm{OR}) / \mathrm{CI} 95$ & $\mathrm{~b}(\mathrm{OR}) / \mathrm{CI} 95$ & $\mathrm{~b}(\mathrm{OR}) / \mathrm{CI} 95$ & $\mathrm{~b}(\mathrm{OR}) / \mathrm{CI} 95$ \\
\hline \multirow{2}{*}{$\begin{array}{l}\text { Anticipated age-at-death regressed on } \\
\text { street code }\end{array}$} & $-9.623^{* *}$ & $-10.569 * *$ & $-10.514 * *$ & $-8.261 * *$ & $-8.902^{* *}$ & $-9.536 * *$ \\
\hline & {$[-12.495,-6.752]$} & {$[-15.746,-5.391]$} & {$[-13.898,-7.130]$} & {$[-12.078,-4.444]$} & {$[-12.838,-4.967]$} & {$[-13.959,-5.112]$} \\
\hline \multirow[t]{2}{*}{ Test for equality of OLS coefficients } & \multicolumn{2}{|c|}{$z=.115(p=.908)$} & \multicolumn{2}{|c|}{$z=-.405(p=.658)$} & \multicolumn{2}{|c|}{$\mathrm{z}=.083(\mathrm{p}=.934)$} \\
\hline & $3.733^{* *}$ & 7.180 & $3.193^{* *}$ & $5.327^{*}$ & $3.810^{* *}$ & $5.198^{*}$ \\
\hline Dead by 35 regressed on street code & {$[1.773,7.863]$} & {$[.648,79.551]$} & {$[1.711,5.957]$} & {$[1.361,20.854]$} & {$[1.457,9.959]$} & {$[1.561,48.189]$} \\
\hline
\end{tabular}

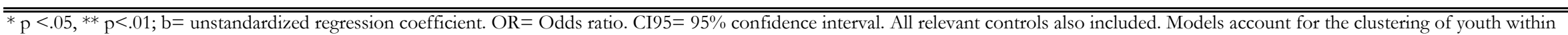
neighborhoods. Test for equality of OLS coefficients was conducted using test specified by Paternoster et al., 1998. 